\title{
Classification and Synoptic Analysis of Subtropical Cyclones within the Northeastern Atlantic Ocean*
}

\author{
JuAN J. GONZÁLEZ-ALEMÁN AND FranCISCO VALERO \\ Departamento de Física de la Tierra, Astronomía y Astrofísica II, Universidad Complutense de Madrid, Madrid, Spain
}

FRANCISCO MARTÍN-LEÓN

Agencia Estatal de Meteorología, Madrid, Spain

JENNI L. EVANS

Department of Meteorology, The Pennsylvania State University, University Park, Pennsylvania

(Manuscript received 6 April 2014, in final form 23 December 2014)

\begin{abstract}
Since more research is needed on subtropical cyclones (STCs) formed within the North Atlantic eastern basin, this survey analyzes them from a synoptic point of view, on a climatological basis, with the main aims of studying their common features, complementing other studies of these storms in the North Atlantic, and aiding the forecasting community. Fifteen cases of STCs were identified during the period 1979-2011 by applying a set of criteria from two databases. Composite analysis reveals that an extratropical depression acts as a precursor when it is isolated from the westerlies and then suffers a deepening when becoming subtropical instead of decaying through occlusion. This process is accompanied by an atmospheric circulation, within the North Atlantic, whose main feature is characterized by notable departures from the climatological pattern with a statistically significant anomalous high pressure to the north of the STCs. Three conceptual models of synoptic pattern of subtropical cyclogenesis are derived and show that these departures appeared because the westerly circulation moves poleward and/or the flow has a great meridional component, with the possibility of a blocked flow pattern occurring. Moreover, the identified STCs predominantly formed in a highly sheared $\left(>10 \mathrm{~m} \mathrm{~s}^{-1}\right)$ environment with low sea surface temperature values $\left(<25^{\circ} \mathrm{C}\right)$, which differs from the dominant features of STCs in the North Atlantic, especially within its western region. Finally, a recent (2010) STC, identified by the authors, is synoptically discussed in order to achieve a better interpretation of the general results.
\end{abstract}

\section{Introduction}

Subtropical cyclones (STCs) are low pressure systems showing characteristics of both tropical and extratropical cyclones, thus being between the theoretical extremes of cyclones. They have a hybrid thermal

\footnotetext{
* Supplemental information related to this paper is available at the Journals Online website: http://dx.doi.org/10.1175/ JCLI-D-14-00276.s1.

Corresponding author address: Juan J. González-Alemán, Dpto. Física de la Tierra, Astronomía y Astrofísica II, Facultad Ciencias Físicas, Universidad Complutense de Madrid, Ciudad Universitaria, 28040 Madrid, Spain.

E-mail: juanjego@ucm.es
}

structure with cold upper-tropospheric and warm lowertropospheric thermal anomalies as main feature. In recent years, there has been a growing interest in STCs because of their recognition as damaging weather systems, such as pre-Hurricane Karen's landfall over Bermuda in October 2001 (Steward 2001; Guishard et al. 2007) to mention just one example. They tend to develop in environments with little low-level baroclinicity in conjunction with diabatic processes.

The formation, development, maturity, and decay of cyclones have been studied for decades, and it was generally believed that tropical cyclones had a life cycle that was distinct from extratropical cyclones. For instance, midlatitude cyclones grow mainly because of baroclinic instability, which requires that there are horizontal temperature gradients and vertical wind 
shear, and then decay as this instability is removed (Bjerknes and Solberg 1922; Charney 1947; Eady 1949; Holton 2004). The thermal structure is asymmetrical, with cold advection generally to the north and to the west of the surface low, and warm advection to the south and to the east; if the cyclone is cut off from the westerlies, the thermal structure will have a deep cold core located over the surface pressure minimum. Satellite imagery of baroclinic cyclones reveals an asymmetric cloudiness pattern associated with horizontal thermal contrast.

Unlike extratropical cyclones, tropical cyclones develop in a barotropic environment with no important horizontal thermal gradients, depending strongly on latent and sensible heat fluxes from the ocean (Charney and Eliassen 1964), since their main source of potential energy is the thermodynamic imbalance between the atmosphere and the underlying ocean (Ooyama 1969; Emanuel 1988). They are governed by latent heat release through cumulus convection (Kuo 1965), and the mechanism of air-sea interaction (Emanuel 1986; Rotunno and Emanuel 1987) is a crucial requirement for their intensification. Tropical cyclones have a suitable development in environments with large-scale low-level convergence and upper-level divergence, small amounts of vertical wind shear, high values of low-level vorticity that may be associated with large horizontal shear, and conditions favorable for barotropic instability (McBride and Zehr 1981). The thermodynamic structure in the vertical has a well-defined warm deep core above the center, and satellite imagery reveals an eyelike feature and an axisymmetric shape.

However, it seems that there is no sharp dividing line between tropical and midlatitude cyclones. In this way, Davis and Bosart (2003) outlined a new mechanism for the development of a tropical cyclone, linking both classical archetypes of cyclones. They called this process tropical transition, whereby a baroclinically induced surface depression may initiate via quasigeostrophic dynamics and amplify through convective diabatic heating to build a warm thermal core from the lower troposphere upward once the development and maintenance of convection near the center is established. The hybrid nature of these cyclones, with a cold core aloft and a warm core near the surface, is characteristic of STCs, which results from the lack of sustained convection near the cyclone center, unlike tropical cyclones. Thus, the distinction between a subtropical depression that goes through its life cycle in a sheared environment and a tropical cyclone that forms via the tropical transition process is often subtle.

One of the major justifications for the study of STCs is that they are associated with both damaging winds and rainfalls and the public expect warnings on such systems. Indeed, the motivation of this study is as a result of the landfall of an STC over the Canary Islands and the Iberian Peninsula at the beginning of February 2010. Since this event was unusual in that region, knowing whether there were more STC cases in the past or it was a unique occurrence is necessary in order to provide a context for STC development of use to the forecasting community, especially in the eastern part of the North Atlantic (ENA), where they are less known and have not been studied as a whole. In addition, this study will serve as a basis for creating a future objective climatology of STCs over this basin. In contrast, STCs have been researched by Guishard et al. (2007) near Bermuda, by Evans and Guishard (2009) within the western North Atlantic (WNA), and by Guishard et al. (2009) over the entire North Atlantic basin. Apart from the North Atlantic, they have been also studied in other regions such as the South Atlantic (Evans and Braun 2012), central Pacific (Otkin and Martin 2004), and Tasman Sea (Holland et al. 1987; Browning and Goodwin 2013). Hereafter, the reader should note that any reference to characteristics of STCs over other regions will be based on these studies, although they will not be quoted to avoid excessive repetition of references.

This survey analyzes STCs formed over the ENA basin during the last three decades from a synoptic point of view, on a climatological basis, with the objectives of 1) highlighting their common features when they evolve over this basin, 2) complementing and contrasting the studies of STCs mentioned above within the North Atlantic, and 3) determining the conditions under which ENA STCs occur, thus providing support for the successful forecasting of such system. These aims are addressed by constructing a database of STCs based on specific criteria, exploring the dynamics with the aid of composite analysis, and classifying the events according to environmental parameters and synoptic patterns. Data used and our methodology are documented in section 2. The temporal and spatial characteristics of the STC cases are presented in section 3 . In sections 4 and 5 , respectively, the composite analysis and stratification of the STCs based upon their genesis environments are presented. A synoptic pattern classification is proposed in section 6 in order to facilitate the identification of the atmospheric patterns that may favor the subtropical formation. For illustrative purposes and to complement the general results, the STC formed in 2010 is described as a case study in section 7, detailing its synoptic evolution and some characteristics related to the other sections. In addition, the consideration of this cyclone as subtropical with the inclusion in our dataset is justified in this section, which is the main reason for selecting 
this cyclone for further analysis. Finally, the results are summarized in section 8 .

\section{Data and methodology}

A set of STCs formed within the ENA is studied herein with the main objective of examining its common climatological and synoptic features. For this purpose, ERA-Interim (Dee et al. 2011) gridded data (sampled to $0.75^{\circ} \times 0.75^{\circ}$ resolution) are utilized.

\section{a. Databases used}

Two databases for the identification of STCs in the ENA basin are used in this survey. They are compared in section $2 b$. On the one hand, the first and only objective STC climatology within the North Atlantic (hereinafter referred to as ERA-40 climatology), built by Guishard et al. (2009), is employed. Only STCs formed over the domain $20^{\circ}-40^{\circ} \mathrm{N}, 30^{\circ} \mathrm{W}-0^{\circ}$ were selected. Cyclones are included in the climatology if they do the following:

1) Attain gale-force winds $\left(17 \mathrm{~m} \mathrm{~s}^{-1}\right)$ on the $925-\mathrm{hPa}$ surface at some time during its life cycle, within the $20^{\circ}-40^{\circ} \mathrm{N}$ latitude band.

2) Exhibit a hybrid structure for at least $36 \mathrm{~h}$, as determined by the cyclone phase diagram (CPS; Hart 2003) with the criteria of $-\left|V_{T}^{L}\right|>-10$ and $-\left|V_{T}^{U}\right|<-10$. This feature is illustrated with examples in sections $2 \mathrm{c}$ and 7.

3) Become subtropical (i.e., attain a hybrid structure) within $24 \mathrm{~h}$, if identified first as a purely cold- or warm-core system.

On the other hand, STCs identified by National Hurricane Center (NHC) were added as well. This NHC database (hereinafter referred to as the NHCHURDAT database) was obtained by means of the IBTrACS project (revision v03r01) (Knapp et al. 2010). We used only STCs formed over the domain between $40.5^{\circ} \mathrm{W}$ and $0^{\circ}$ with no limit on latitude, from 1979 to 2011, and those that attained subtropical storm intensity $\left(17.5 \mathrm{~m} \mathrm{~s}^{-1}\right.$, using a 1 -min average). This last criterion is used to be more consistent with ERA-40 climatology (first criterion).

NHC policy for classification of STCs has been the same since 1975, with the use of the first and only objective Hebert-Poteat (HP) satellite classification system (Hebert and Poteat 1975). This satellite recognition technique was implemented, as a complement to the Dvorak technique for tropical cyclone intensity classification (Dvorak 1975), for estimating STC intensity. Its goals were to use cloud features associated with STCs in order to be able to 1) distinguish them from tropical cyclones in the formative stages, 2) estimate their intensity, and 3) have criteria that would intermesh with the Dvorak technique when systems become tropical. The method outlined has elements of subjectivity intrinsic to this type of categorization, yet its application is supported by its use by forecasters experienced in using satellite classification techniques. Although satellite resolution has improved vastly since it was developed, the HP technique provides the only guidance for remote sensing of different intensities of STCs.

Apart from this technique, NHC has started to use new tools and data sources that have become available in the past few years (Landsea 2007), one of which is the above-mentioned CPS. The CPS is a three-dimensional descriptor of the cyclone structure, in which structure types are thermodynamically classified by reference to their horizontal symmetry $(B$ : thermal symmetry parameter) and vertical thermal structure $\left(-V_{T}^{L},-V_{T}^{U}\right.$ : thermal wind parameters) (Hart 2003). Despite its advantage of being objective, this diagnostic tool should be used in conjunction with synoptic fields, satellite imagery, and other analysis tools in order to produce an evaluation of the cyclone structure type as reliable as possible (Guishard et al. 2009).

Our database of STCs identified within the ENA was increased by adding the STC occurred in 2010, which has been identified by the authors in this study. In section 7 , both the recognition of this cyclone as subtropical system and its inclusion in our study are justified in detail.

\section{b. Comparison of the NHC-HURDAT database with ERA-40 climatology}

The way a cyclone is included slightly differs depending on the database to which it belongs. In ERA-40 climatology, model reanalysis and the CPS are used to isolate cyclones that are unambiguously identified as STCs by applying an objective, consistent, and largely automated method. In contrast, the NHC-HURDAT database (Jarvinen et al. 1984) does not incorporate any objective methodology to include a cyclone since it is derived primarily from subjectively reanalyzed operational data and thus it may be inconsistent and biased.

However, ERA-40 climatology and NHC-HURDAT database consider STCs nearly the same structure. For instance, they both use the HP technique (in ERA-40 climatology, it is used to verify the nature of the storms). In addition, during the last decade NHC has focused more on the thermal structure of cyclones thanks to the advent of the mentioned new tools. This, together with the information provided in section $2 \mathrm{c}$, allows justifying the use of both databases since the objective of this study is related to the phenomena that favor the successful development of hybrid structures that lead to STCs, more than to specific aspects of their definition. This 
latter issue, especially in the case of ENA STCs, needs more research and discussion in order to deal in greater depth with their definition. This is why part of this study is focused on the creation of a future objective climatology of this type of phenomena in the eastern part of North Atlantic, by gaining insight into such processes.

The overlap or coincidence between the two databases during the period 1957-2002 is considerable but not perfect (Guishard et al. 2009), as would be expected as a result of the different techniques and criteria used. ERA-40 climatology exclude systems with subtropical characteristics for a variety of reasons-for instance, those systems with no gales associated, those formed over land, or those having hybrid characteristics not observed for the required $36 \mathrm{~h}$, among others. As to NHCHURDAT database, this excludes systems with marked frontal character at surface. Therefore, the selection methodology used herein has the advantage of identifying as many STCs as possible in the region of study, which is the main reason for the inclusion of both datasets.

Comparing quantitatively the identification of STCs in the two databases, it can be seen that 92 (361) out of 453 cyclones were operationally deemed subtropical (tropical) in the NHC-HURDAT database. Also, 197 STCs were found in ERA-40 climatology; 65 of the 92 STCs found in NHC-HURDAT did not meet the STC criteria in ERA-40 climatology. Conversely, 53 are named cyclones (subtropical or tropical) in NHCHURDAT database that overlap with ERA-40 climatology; 26 of these 53 did meet ERA-40 STC criteria but were not labeled as subtropical but as tropical. The remaining 27 (i.e., 92 - 65) were identified as STC in both databases, which is thus the key overlap and encompasses $29 \%(27 / 92)$ of the NHC-HURDAT database and 14\% (27/197) of the ERA-40 climatology. It is important to note that this analysis is based on the period 1957-2002 (including the presatellite era). Nevertheless, 1979-2002 is the period common to the STC databases used in the present study, a period when satellite observations were commonly used. Therefore, it is likely that the percentage overlap shown above could be increased by an examination of cyclones only during the period 1979-2002 because of the advent of routine satellite observations during this period.

It is highly likely that more STCs than those obtained herein have formed during the period of study of both databases (1979-2002 for ERA-40 climatology and 1979-2011 for the NHC-HURDAT database). The criteria imposed to identify STCs in the ERA-40 climatology are rather restrictive, especially within the ENA region. Moreover, STCs have been inconsistently handled by NHC with a high degree of subjectivity as evidenced, for instance, in the policy for naming or issuing advisories on them, especially in the 1980s and 1990s. For instance, the abovementioned STC formed in 2010 was not studied by NHC. This is one of the reasons why this cyclone has been individually included as a case study in section 7 .

\section{c. Analysis of the STCs from the NHC-HURDAT database in the terms of the CPS}

In this subsection, an analysis of two examples of cyclones detected in NHC-HURDAT database that are not included in ERA-40 climatology, and that have been used to carry out this study (see section 3 ), is provided. This analysis, based on the CPS, serves as a means of justifying the inclusion of the five cyclones from the NHC-HURDAT database, which allows one to add consistency to the use of both databases. For simplicity, the analysis of the other three cyclones is not shown herein given that they have a similar behavior.

\section{1) STC4 (1990)}

According to Fig. 1a, this STC started as a gale-force extratropical system at 0000 UTC 3 August in the CPS based on ERA-40. Then, after $30 \mathrm{~h}$ it acquired hybrid/ subtropical structure $\left(-\left|V_{T}^{L}\right|>-10\right.$ and $-\left|V_{T}^{U}\right|<-10$; shallow warm core) through the tropical transition process by 0600 UTC 4 August and became extratropical again at 0000 UTC 6 August.

This system was therefore not included in ERA-40 climatology because the third criterion listed in section 2a was not fulfilled. However, it does meet the first and second (the most important one) criteria. The third criterion was included in ERA-40 climatology for operational forecasting considerations since the intention was to filter out systems that, previously to the achievement of the hybrid structure, had gale-force winds and thus systems that would have already likely been monitored by forecasters, limiting the chances of a surprise storm. In other words, the intention in ERA40 climatology was to study STC cases essentially formed in situ. However, we emphasize that this is not the aim of this survey, which is to study all STC cases occurred in the ENA basin instead, since there is less knowledge about ENA STCs and forecasters are less aware of them. We are more interested in the phenomenon itself, that is, the development of enough convection to transition into a subtropical system (acquisition of a hybrid structure). This is the reason why the third criterion has been omitted in this study.

\section{2) STC14 (2007)}

According to Fig. 1b, this gale-force cyclone started with a hybrid structure $\left(-\left|V_{T}^{L}\right|>-10\right.$ and $-\left|V_{T}^{U}\right|<-10$; shallow warm-core) at 0000 UTC 3 October in the CPS 

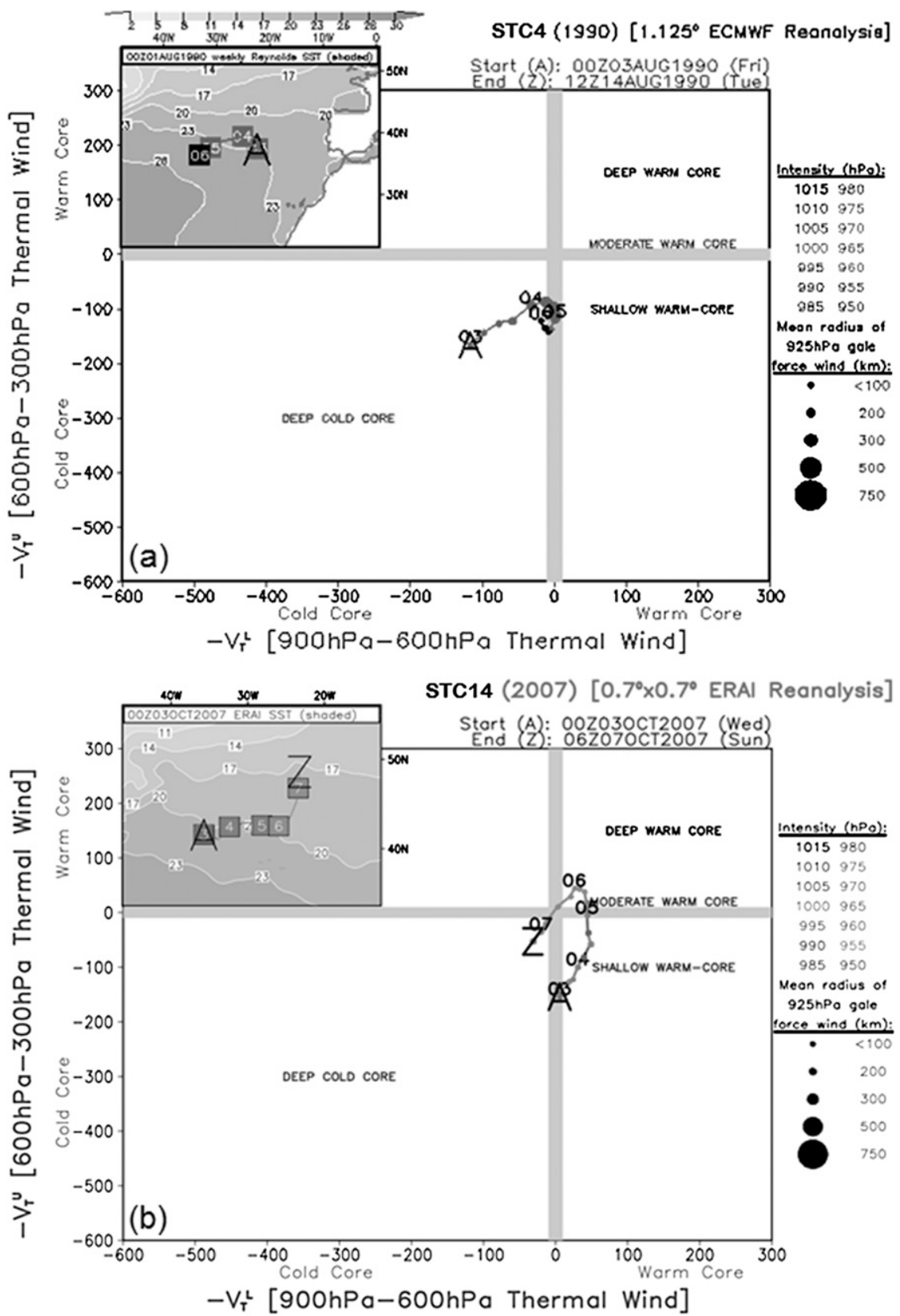

FIG. 1. (a) ERA-40 of STC4 and (b) ERA-Interim of STC14, plotted in the CPS ( $V_{T}^{L}$ vs $V_{T}^{U}$ ). The A indicates the beginning of the plotted life cycle within the reanalysis and the $\mathrm{Z}$ indicates the end. A marker is placed every $6 \mathrm{~h}$. The shading of each marker indicates cyclone MSLP intensity and the size of the circular marker indicates the relative size (mean radius) of the 925-hPa gale-force $\left(>17 \mathrm{~m} \mathrm{~s}^{-1}\right)$ wind field. Positions at 0000 UTC are labeled with the day. Because of visual considerations, the life cycle of STC4 has been stopped at 0000 UTC 6 Aug, before the time Z [Available online for (a) at http://moe.met.fsu.edu/cyclonephase/archive/1990s/ and for (b) at http://moe.met.fsu.edu/cyclonephase/archive/2007/gifs/aleman22007/].

based on ERA-Interim. After $48 \mathrm{~h}$ it clearly developed a warm core $\left(-\left|V_{T}^{L}\right|>-10\right.$ and $\left.-\left|V_{T}^{U}\right|>-10\right)$ in upper levels, which gave it a tropical cyclone structure by 0000 UTC 5 October. Later on, it acquired a cold-core structure at 0000 UTC 7 October. This system would have been included in the ERA-40 climatology, if not for the fact that the cyclone did not attain gale-force winds within the $20^{\circ}-40^{\circ} \mathrm{N}$ latitude band, which is 
TABLE 1. STCs identified from ERA-Interim during the period of 1979-2011. The number in parentheses after the names of the cyclones indicates the database from where the cyclone comes: 1 for the climatology of Guishard et al. (2009) and 2 for the NHCHURDAT database. STC15 was identified by the authors.

\begin{tabular}{|c|c|c|c|c|}
\hline Storm & Formation time $\left(t_{0}\right)$ & $\operatorname{MSLP}(\mathrm{hPa})$ & Lat $\left({ }^{\circ} \mathrm{N}\right)$ & Lon $\left({ }^{\circ} \mathrm{W}\right)$ \\
\hline STC1 (1) & 0000 UTC 12 Nov 1981 & 1010.7 & 29.25 & 27.75 \\
\hline STC2 (1) & 0600 UTC 16 Mar 1984 & 1014.0 & 39.75 & 26.25 \\
\hline STC3 (1) & 0000 UTC 2 Mar 1988 & 1004.2 & 30.00 & 9.75 \\
\hline STC4 (2) (pre-Edouard) & 1200 UTC 3 Aug 1990 & 1009.4 & 39.75 & 22.50 \\
\hline STC5 (1) & 0600 UTC 4 Dec 1991 & 991.2 & 32.25 & 24.00 \\
\hline STC6 (1) & 0000 UTC 17 Feb 1996 & 1013.6 & 27.00 & 20.25 \\
\hline STC7 (1) & 1800 UTC 19 Feb 1996 & 1012.6 & 27.75 & 26.25 \\
\hline STC8 (1) & 1800 UTC 4 Mar 1996 & 999.0 & 31.50 & 23.25 \\
\hline STC9 (1) & 0000 UTC 29 Jan 1997 & 1004.3 & 36.00 & 26.25 \\
\hline STC10 (1) & 0000 UTC 6 Mar 2000 & 1014.0 & 28.50 & 20.25 \\
\hline STC11 (2) & 1200 UTC 4 Oct 2005 & 1012.1 & 36.00 & 30.00 \\
\hline STC12 (2) (pre-Vince) & 0600 UTC 8 Oct 2005 & 1002.6 & 32.25 & 21.00 \\
\hline STC13 (2) (pre-Delta) & 1800 UTC 22 Nov 2005 & 980.2 & 30.75 & 40.50 \\
\hline STC14 (2) & 0600 UTC 6 Oct 2007 & 998.9 & 42.75 & 25.50 \\
\hline STC15 & 1800 UTC 29 Jan 2010 & 996.3 & 30.75 & 31.50 \\
\hline
\end{tabular}

a requirement added in ERA-40 climatology only to reduce the possibility of introducing pure extratropical or tropical systems and therefore is not applied herein.

\section{d. Methodology}

Once STCs are identified, the methodology associated with this survey has been characterized by the determination of

1) maps of geopotential height at $300 \mathrm{hPa}$ and mean sea level pressure (MSLP) during the life cycle of the cyclones with the purpose of performing the synoptic classification;

2) composite maps of geopotential height at $300 \mathrm{hPa}$ and MSLP fields in order to carry out the analysis;

3) monthly-mean reanalysis fields for the period of 1979-2012 to define the mean climate structure in constructing the composite anomalies; and

4) sea surface temperature (SST) and vertical wind shear (WS) within a domain centered at the low pressure minimum. This will enable the environmental classification.

The three last steps were completed following Evans and Guishard (2009), with the objective of comparing with their results. Yet the calculation of deep layer WS has differed in this study. Calculating WS by layers was considered more robust than by levels. Thus, WS is calculated as

$$
\mathrm{WS}=\sqrt{\left(u_{U}-u_{L}\right)^{2}+\left(v_{U}-v_{L}\right)^{2}},
$$

where the subscript $U$ is for the average of 200, 250, and $300 \mathrm{hPa}$ (upper layer), whereas the subscript $L$ is for the average of 700,850 , and $925 \mathrm{hPa}$ (low layer). Wind speed components are denoted by $u$ and $v$.

\section{Identified subtropical cyclones}

A set of 15 STCs formed within the ENA have been detected during the period of 1979-2011. Note that ERA-40 climatology as used here only covers the period of 1979-2002. Nine of those belong to ERA-40 climatology and five belong to the NHC-HURDAT database. The last cyclone is the STC that originated in 2010 and is identified by the authors in this study. Table 1 contains further information from ERA-Interim about the STCs identified. It is worth noting that STC4, STC12, and STC13 constituted the early stages of Tropical Storm Edouard (Case 1990), Hurricane Vince (Franklin 2006), and Tropical Storm Delta (Beven 2006), respectively.

Figure 2a depicts the tracks of the cyclones and their location at the formation time $t_{0}$, that is, the first moment when they were designated as subtropical systems in the databases (subtropical storms in NHC-HURDAT). It highlights the erratic features of the movements of the cyclones, which is in reality a manifestation of autonomy or isolation of the cyclones from the basic flow in middle latitudes. In contrast, STCs that developed within the WNA exhibit far more linear paths. This difference arises as a result of the existence of a climatological trough over this region (see Fig. 4), which is indicative of the continuous crossing of troughs steering STCs toward the east. In contrast, troughs frequently evolve into cyclones isolated from the westerly circulation (cutoff lows) over the ENA basin. Indeed, Nieto et al. (2005) noted that one of the three preferred areas of cutoff low occurrence in the Northern Hemisphere extends through southern Europe and the eastern Atlantic coast. The idea of the baroclinic origin of STCs within the ENA basin is further developed in the following sections. 
(a) Initial Geographic Locations and Tracks

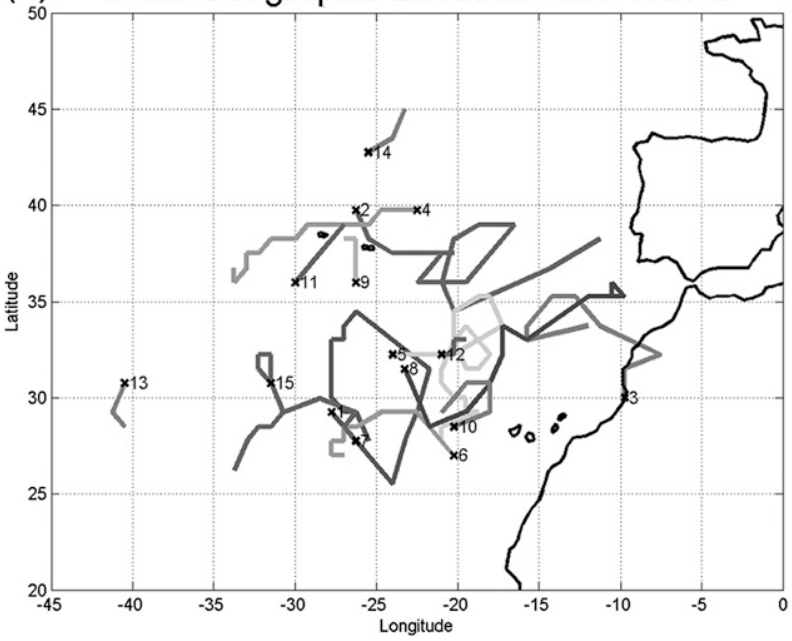

(b)

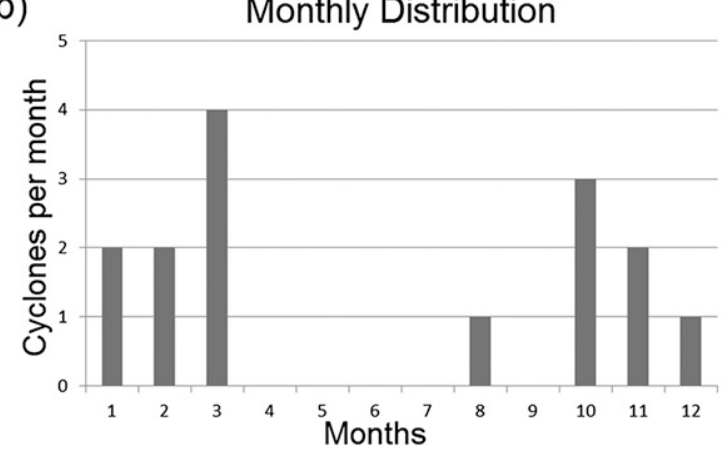

FIG. 2. (a) Initial geographic locations, tracks and (b) monthly distribution of the STCs identified within eastern basin of the North Atlantic during the period of 1979-2011. The crosses indicate the position of the cyclones at the time of their formation $\left(t_{0}\right)$ and the numbers are associated with the cyclones' names as described in Table 1 . The tracks have been only displayed within the time interval when the lows were considered to be subtropical cyclones in the databases.

Temporal analysis (Fig. 2b) suggests that subtropical cyclogenesis has a preferred seasonality. Note that 14 out of the 15 cyclones have in fact formed from October to March, which would be consistent with their baroclinic origin since midlatitude circulation moves southward in winter and therefore cutoff lows would be more likely to reach low mid- and subtropical latitudes. However, cutoff lows seem to be more frequent in summer over the ENA basin and Mediterranean Sea (Nieto et al. 2005). This inconsistency is likely to be as a result of the difference in temperature between SST and the cold air in the upper troposphere associated with depressions. This difference would be bigger in winter mainly because of much deeper upper-level cold lows, causing a greater destabilization of the atmosphere, and thus the associated convection would be more significant than in summer. The more convection originates within the center of the cyclone, the more likely its transition to a subtropical system (Guishard et al. 2009). Nevertheless, more research on this issue is needed to clarify the relation between cutoff lows and STCs within the ENA.

Another issue worth highlighting is the formation of STC4 in August since it was the only STC formed in summer and also because it then evolved into a tropical cyclone. By examining its synoptic history (not shown), it can be seen that it was the digging of a trough near the Azores, with the subsequent formation cutoff low, that led to the development of the STC, consistent with the genesis mechanism of the rest of the cyclones. This low then remained stationary for three days, which helped it to make a transition to its tropical stage.

A comparison with other studies in order to contrast our temporal distribution of the cyclones is needed. STCs within the entire North Atlantic predominantly formed during the midhurricane or warm season up to its end (i.e., from September to November) as a consequence of WNA STC prevalence over the North Atlantic. WNA STCs mostly form during this time of the year because relatively warm SSTs reach their northernmost extent, which contributes to the fact that the overlap between the baroclinic zone and the warm SST zone is as large as possible, particularly in October (Guishard et al. 2009). In fact, Bermuda subtropical storms, as part of the WNA STCs, show a remarkable peak in September. However, Fig. 2b does not display any leading peak in autumn, but shows the predominance of ENA STCs events in winter, which may give an idea of the differences between both types of STCs since WNA STCs tend to form in the season when SSTs are warmest whereas ENA STCs tend to form when midlatitude circulation reaches its southernmost extent. It can be therefore inferred that the major factor (SST or midlatitude circulation) that leads to the formation of an STC may differ depending on the basin, which is a result that will be also supported by the environmental classification shown in section 5. Although warm SSTs and midlatitude circulation (cutoff lows) would be considered to be necessary factors for the successful development of an STC, future work is needed to clarify the key (necessary and sufficient) factors that determine whether a low would evolve into an STC or not (Evans and Guishard 2009; Guishard et al. 2009), especially within the ENA basin.

\section{Composite analysis}

Geopotential height at $300 \mathrm{hPa}$ and MSLP composites have been represented in this section to describe the common synoptic features arising within the North Atlantic when STCs formed at $t_{0}$ (North Atlantic basin 
composites; section 4a) and in the surroundings of the cyclones following their tracks (storm-centered composites; section $4 \mathrm{~b}$ ). The anomaly composites have been also constructed so as to reveal more detailed environmental features that are not evident in the non-anomalycomposited fields on their own. The anomalies represent departures from long-term ERA-Interim (Dee et al. 2011) monthly-mean values for the period of 1979-2012. To ensure that the synoptic-scale features associated with STC genesis are captured, they are computed over a cyclone-centered (at the MSLP minimum) $30^{\circ} \times 25^{\circ}$ grid in 6-h intervals from $24 \mathrm{~h}$ prior to genesis to $24 \mathrm{~h}$ after-that is, from $t_{0}-24 \mathrm{~h}$ to $t_{0}+24 \mathrm{~h}$. In this regard, it should be noted that the synoptic influence common to all STC cases may not be as obvious as they are in an individual case. With this in mind, it is advisable to perform case studies to complement the compositing approach. Hence, the synoptic evolution of STC15 has been analyzed in section 7 .

\section{a. North Atlantic basin composites}

Figure 3a reveals the main descriptive feature of the atmospheric circulation pattern in the North Atlantic basin at the moment when the 15 STCs formed. As can be seen from this figure, a trough to the south of the ENA is located just to the southwest of the Iberian Peninsula and involves a ridge to the north, with its axis just to the west of the British Isles. This upper-level pattern influences the low-level pattern to strengthen a high pressure structure centered at the southwest of the British Isles that spreads over a large extent of the ocean. There is also an area of low pressure below the trough, associated with the STCs. Therefore, Fig. 3a shows that these STCs form in a meridional trough, with the westerly midlatitude flow blocked over Europe and North Africa by constructive reinforcement between the subtropical anticyclone and the high pressure ridge in the extratropical longwave. Such a pattern differs from the long-term climatological one (see Fig. 4). This latter is characterized by an upper subtropical ridge over the ENA basin associated with the Azores high, which provides a wide region of stable climate.

The remarkable anomalies associated with STC formation can be seen in Fig. 3b. It shows a widespread area of negative anomalies just to the west of the Canary Islands associated with the cyclone anomaly, and a broad and band-shaped area of positive anomalies encompassing from Newfoundland to the British Isles and Scandinavia. The positive anomalies are located around $60^{\circ} \mathrm{N}$ whereas the negative anomalies are around $30^{\circ} \mathrm{N}$ (Fig. 3b). This blocked flow pattern (Doblas-Reyes et al. 2002), as described in the nonanomaly composites, is the main feature of the atmospheric circulation over the North Atlantic Ocean when the STCs developed within the eastern basin. In addition, it can be noted that these upper-level anomalies are reproduced significantly at low levels, especially in the case of the anomalous high pressures. The center of this positive surface anomaly is shifted to the east with respect to the upper anomaly (as expected in an extratropical system). In the case of the negative anomaly, its center is just beneath, which is more typical of a tropical circulation. The statistical significance analysis of these anomalies as well as that of Figs. $5 \mathrm{~d}-\mathrm{f}$ (see section $4 \mathrm{~b}$ ) is available in the supplemental material.

To facilitate the interpretation of the composites just described here, three obtained conceptual models of atmospheric patterns when the STCs formed (section 6) and the study of the synoptic evolution of the STC15 (section 7) are included in this survey.

\section{b. Storm-centered composites}

The resulting storm-centered composites are depicted in Figs. 5a-c. They display a relevant structure of the common synoptic environment of the cyclones, which is linked to the atmospheric pattern revealed by the Atlantic composites to a great extent. The presence of an upper trough in the westerlies promotes a quasigeostrophic (QG) forcing for the development of the low pressure at the surface just to the south-southeast of the trough center. This becomes the dominant feature prior to the onset of STC genesis $\left(t_{0}-24 \mathrm{~h}\right.$; Fig. 5a). In each STC case, a trough was likewise evident in proximity to the surface low although not all the troughs were in the same state of evolution at $t_{0}-24 \mathrm{~h}$. There were certain cases in which the trough was amplified, almost forming a cutoff low, whereas there were other cases in which the trough was embedded in the westerlies in a previous stage of a digging trough (i.e., just before it began to amplify). As time passes, the wave at $300 \mathrm{hPa}$ evolves into a closed system and deepens as the upper ridge downstream of the trough weakens through the time (evident in the 926 dam isopleth at $t_{0}+24 \mathrm{~h} ;$ Fig. $5 \mathrm{c}$ ). All these features indicate that the cyclone evolves into a closed low, isolated from the midlatitude circulation. The deepening STC tends to become vertically stacked (Figs. 5a-c), which leads to a lesser QG forcing and a greater diabatic heating forcing associated with the latent heat release provided by convection just below the upper cold air core, and therefore the cyclone adopts a more tropical structure. There is more agreement among the STC cases at $t_{0}+24 \mathrm{~h}$, when a cutoff low was evident in nearly all the cases.

This latter forcing can be explained in terms of the Lagrangian tendency of potential vorticity (PV) due to 


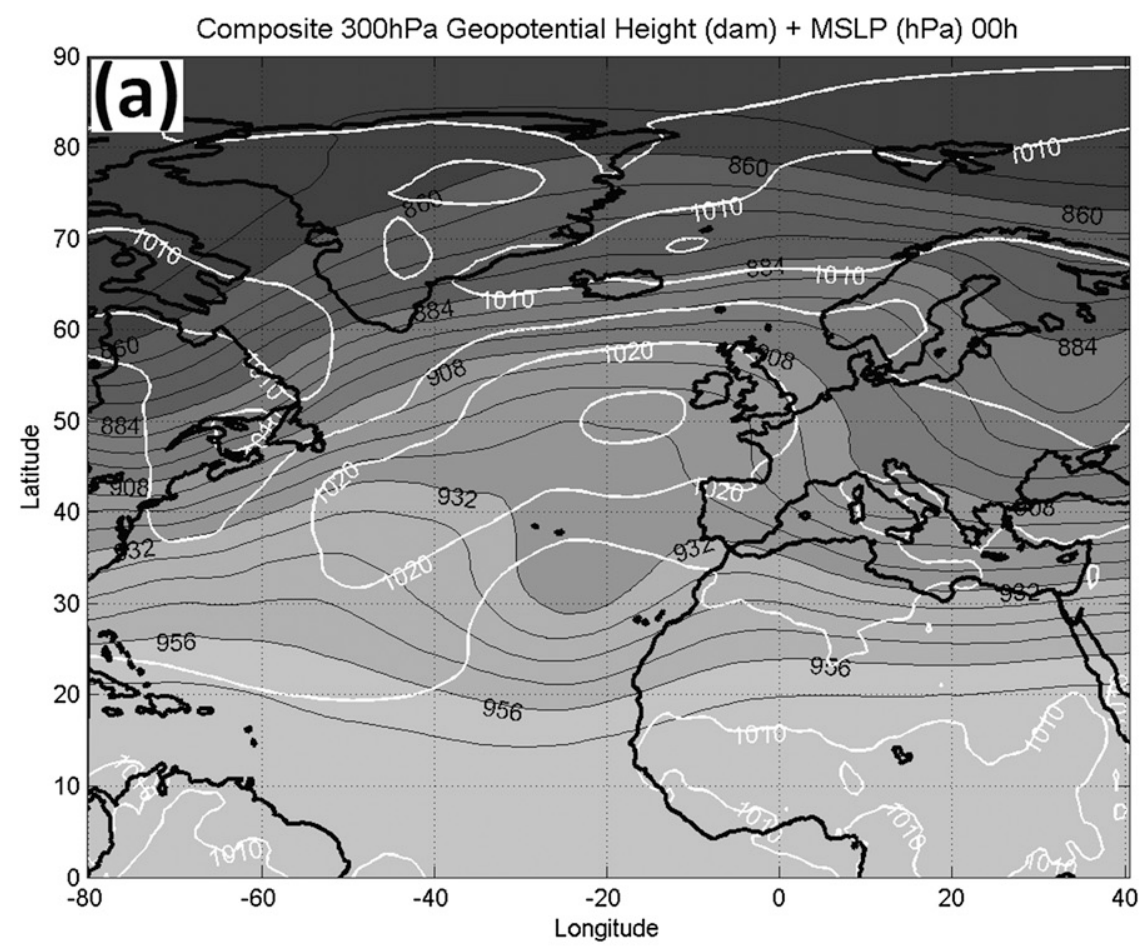

Composite 300hPa Geopotential Height Anomaly (dam) + MSLP Anomaly ( $\mathrm{hPa}$ ) 00h

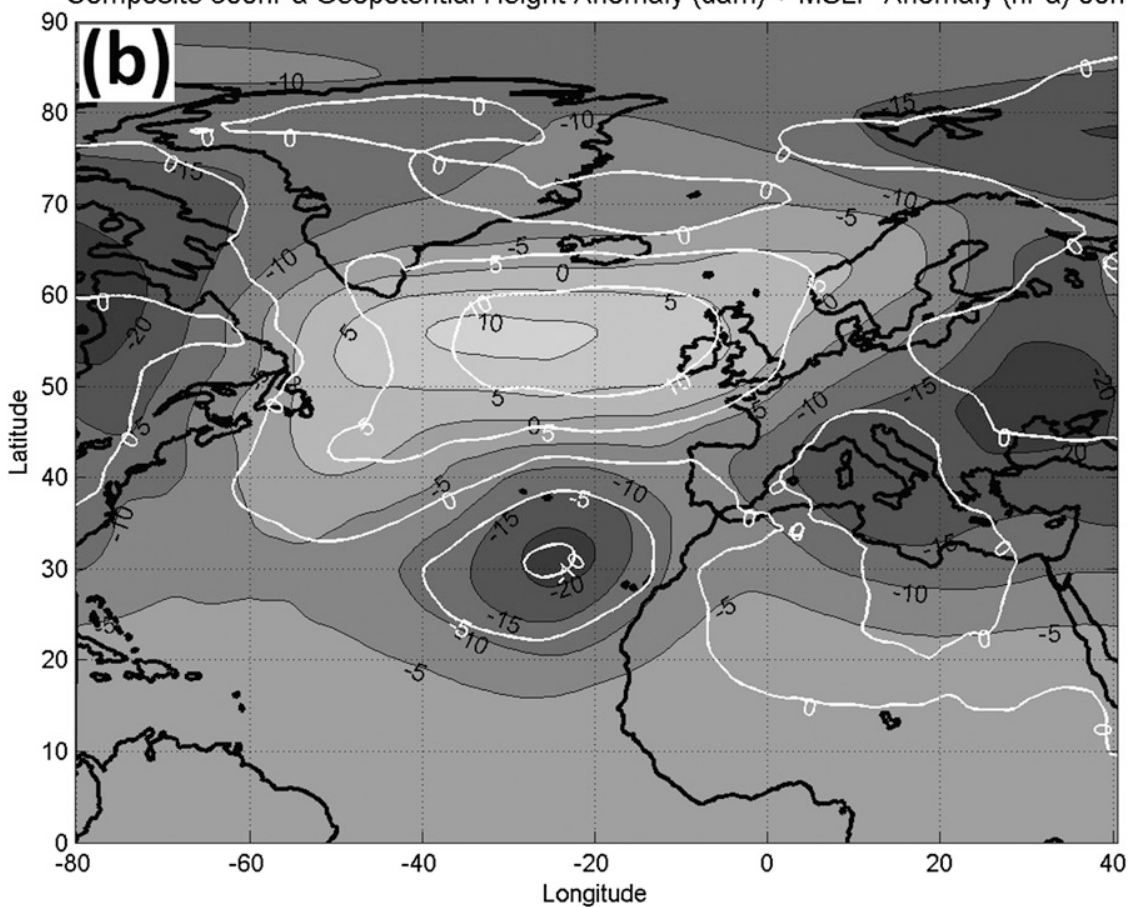

FIG. 3. (a) Composite (all 15 STCs) of 300-hPa geopotential height (shaded and gray contours; dam) and mean sea level pressure (white contours; hPa) at $t_{0}(0 \mathrm{~h})$. (b) Also plotted is the anomaly composite. Statistical significance of (b) is available in the supplemental material. 


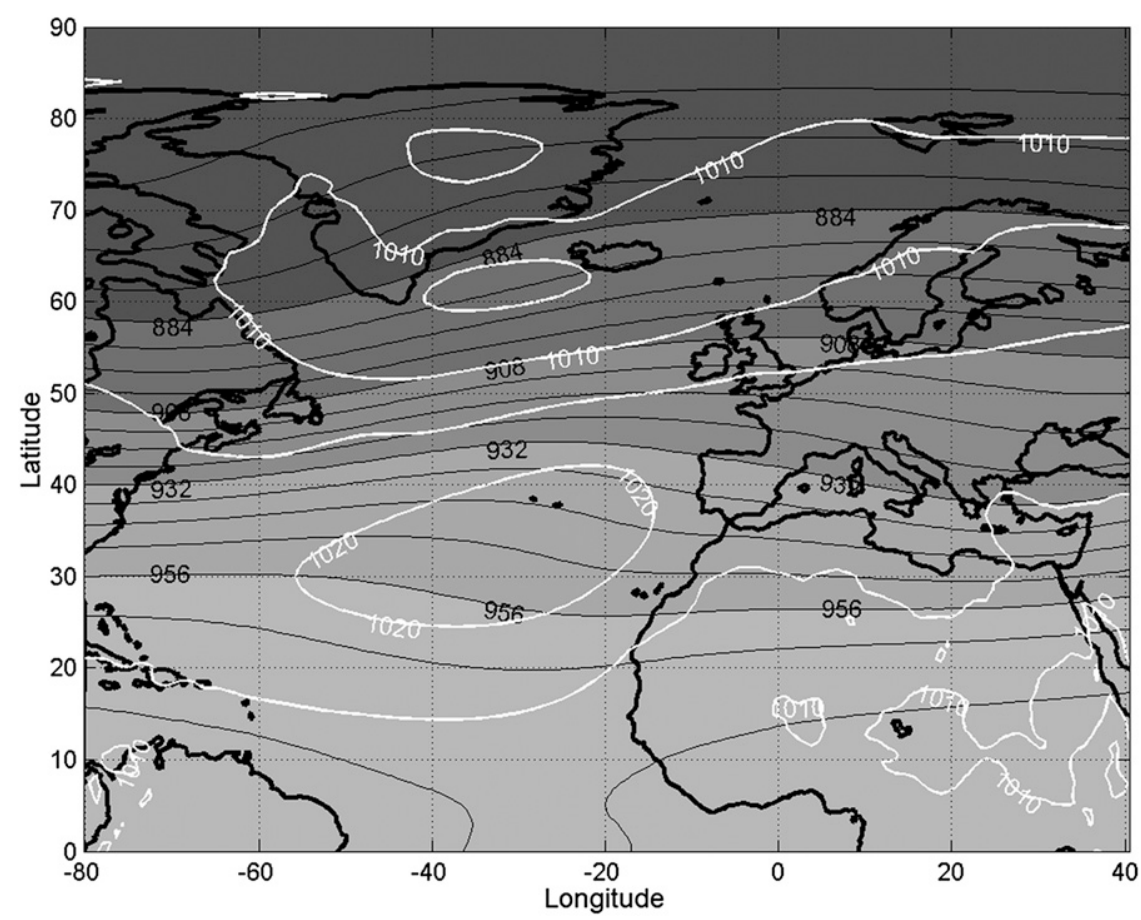

FIG. 4. Long-term (1979-2012) ERA-Interim climatology over the North Atlantic of 300-hPa geopotential height (shaded and gray contours; dam) and mean sea level pressure (white contours; hPa).

a diabatic heat source represented by (Hoskins et al. 1985)

$$
\rho \frac{d \mathrm{PV}}{d t}=\boldsymbol{\eta}_{a} \cdot \nabla \dot{\theta}
$$

where $\rho$ is the atmospheric density, $\boldsymbol{\eta}_{a}$ is the threedimensional absolute vorticity vector, and $\dot{\theta}$ is the diabatic warming rate (i.e., $d \theta / d t$ ). Equation (2) states that potential vorticity can be redistributed vertically by introducing a differential diabatic heat source (e.g., latent heat release) into the column. Assuming that the diabatic heating maximum is situated in the midtroposphere and the absolute vorticity vector is nearly vertical, PV will tend to increase (decrease) in the layer below (above) the heating maximum (Raymond 1992). This heating will involve an anomalously high PV in the lower troposphere with lower values near the tropopause. The deepening of the STC can be thus explained by this forcing since higher PV values in the lower troposphere lead to an increased circulation of the cyclone related to a decreased pressure at its center. This mechanism is in fact consistent with the concept of a warm core lower-tropospheric cyclone, characteristic of STCs, resulting from the large amount of released latent heat. Diabatic effects of cyclone intensification are also observed in extratropical cyclone formation
(Romero 2001) and contribute to the enhancement of their warm-seclusion process as well (Gyakum 1983a,b).

When observing the temporal animation (from $t_{0}-$ $24 \mathrm{~h}$ to $t_{0}+24 \mathrm{~h}$ every $6 \mathrm{~h}$; not shown), the variation of the previously described features are in fact larger once the cyclone acquires subtropical characteristics $\left(t_{0}\right)$, indicating the crucial difference in the structure and environment of the cyclone when this undergoes a transition to a subtropical state. Thus, these results suggest that there exist some extratropical cyclones that become subtropical and generally intensify instead of filling when they are isolated from the westerlies, along their path over the northeastern Atlantic. This process is well documented in the South Hemisphere (Holland et al. 1987; Evans and Braun 2012; Browning and Goodwin 2013). Cutoff lows commonly weaken and occlude as they move toward subtropics and baroclinicity decreases, which differs from the results obtained in this section.

Anomaly composites (Figs. 5d-f) reveal a region of negative anomalies in both fields, associated with the subtropical depressions. These anomalies are initially on the order of $10 \mathrm{hPa}$ in the MSLP and 25 dam in the geopotential height. Both anomalies evolve deepening up to $15 \mathrm{hPa}$ and 30 dam, respectively, which is consistent with the previously described nonanomaly composites. The strengthening and positioning of the positive anomalies just to the north of the negative anomalies, as 

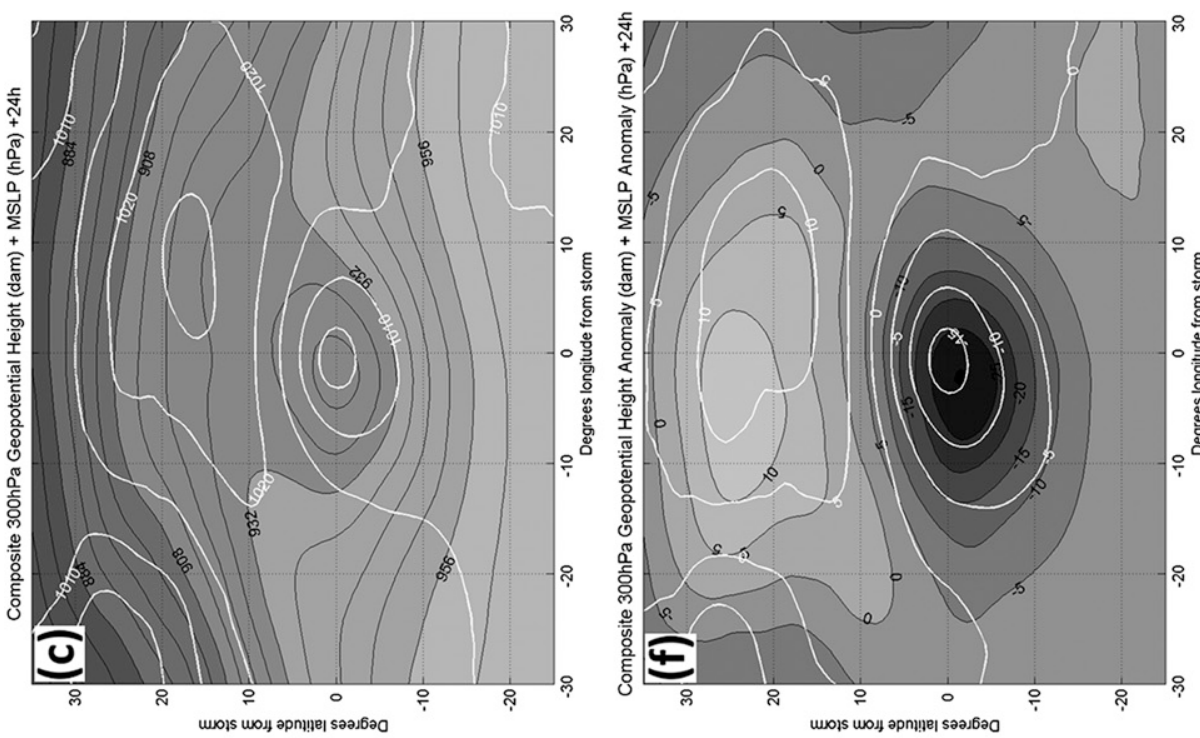

竎

:
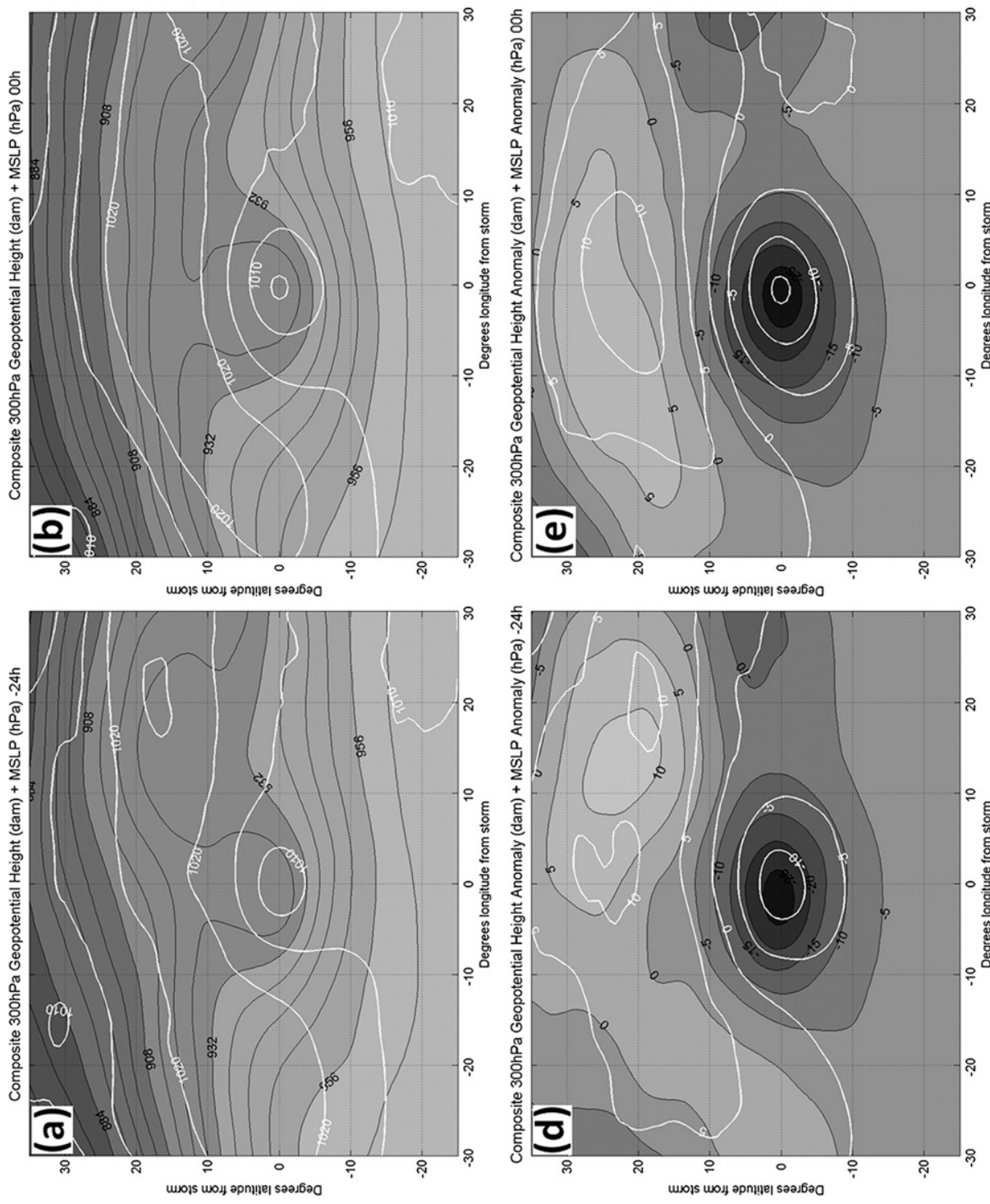

产

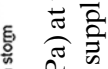

है

要表

产

可

雪.

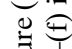

㝕 $\frac{1}{3}$

눙

$\vec{\nabla} 8$

『

สิ

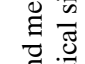

․․ㄹ

สิ

क्षे

e

范实

胥

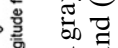

च

嵩 ठ

要

告

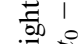

ฮ)

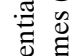

ㅎํㅇ

잉

둔

옹

흥

कै ते

点焉

设

స्త్ర

象

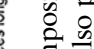

家文

¿

可

苟

ن.

है

in

อ 
time passes, is the most important feature of the anomaly composites. These positive anomalies evolve covering a widespread region of $+10 \mathrm{hPa}$ at $t_{0}+24 \mathrm{~h}$, which would denote the reinforcing of a ridge just to the north of the cyclone and thus a greater blocked flow regime feature.

The synoptic evolution described in the stormcentered composites is consistent with the idea of the isolation from the general circulation that the cyclone undergoes when evolving into a subtropical stage, which would be a requirement for an auspicious development. Furthermore, as with WNA STCs, the greater curvature of the flow observed in the region of the upper-level cyclone, causing anticyclonic shear just to the north of the surface depression, is consistent with a Rossby wave breaking event (Thorncroft et al. 1993). This feature is verified when doing the description of the synoptic history of STC15 in section 7.

In addition, the results just described here are also consistent with the WNA STC composites in that the average cyclone deepens once it acquires a subtropical structure, and the shape of the anomalies tend to resemble each other even though the anomalies are greater here, which is reasonable since the western basin is rather different from the eastern basin in terms of climate. Note that the climatological pattern over the North Atlantic (Fig. 4) is characterized by a subtropical ridge, with its associated Azores high over the eastern basin while a trough is located over the western side. The reinforcing and strengthening of the anomalous high pressure just to the north of the cyclonic anomalies, which Evans and Guishard (2009) considered to be the manifestation of a Rex block pattern, is the main common feature of both studies. Nevertheless, it can be seen that the nonanomaly composites are differentiated from each other, in the sense that western composites do not evolve into a closed upper-level contour despite the fact that both composites have the same contour interval as Figs. 5a-c. This difference would indicate that the evolution of the trough into a cutoff low, or at least into an upper-level closed low, in the WNA is not as common as in the ENA, which reinforces the idea of the difference in the environments between the two basins when STCs form. It is also important to note that composites of Fig. 5 are consistent with results obtained, in MSLP composites, by Browning and Goodwin (2013) for southern secondary low (SSL) events, and by Otkin and Martin (2004) for cold-frontal cyclogenesis/trade winds easterlies (CT) kona lows.

\section{Environmental classification of subtropical cyclogenesis}

An environmental classification of the identified STCs is undertaken in this section. As in the case of
Evans and Guishard (2009), the 15 STC cases have been partitioned into four classes based upon their WS and SST characteristics in the surrounding of the cyclones when they formed (i.e., $t_{0}$ ). These four environments are: tropical (T: $\mathrm{SST} \geq 25^{\circ} \mathrm{C}$, WS $\leq 10 \mathrm{~m} \mathrm{~s}^{-1}$ ), subtropical (ST: $\mathrm{SST} \geq 25^{\circ} \mathrm{C}$, WS $>10 \mathrm{~m} \mathrm{~s}^{-1}$ ), the classical extratropical type $1\left(\mathrm{E} 1 \mathrm{SST}<25^{\circ} \mathrm{C}\right.$, WS $\left.>10 \mathrm{~m} \mathrm{~s}^{-1}\right)$, and the low-shear extratropical type 2 (E2: SST $<25^{\circ} \mathrm{C}$, $\left.\mathrm{WS} \leq 10 \mathrm{~m} \mathrm{~s}^{-1}\right)$. They calculated WS by taking a $5^{\circ} \times 5^{\circ}$ average centered on the cyclone whereas SST averages were calculated for a $2^{\circ} \times 2^{\circ}$ grid box. With our intention of being as consistent as possible with their methodology and because of the different grid resolution $\left(0.75^{\circ}\right)$, for this study we had two alternatives for the size of the grid boxes, which were $1.5^{\circ} \times 1.5^{\circ}$ for SST and $4.5^{\circ} \times 4.5^{\circ}$ for WS, and $3^{\circ} \times 3^{\circ}$ for SST and $6^{\circ} \times 6^{\circ}$ for WS. Table 2 shows that SST is not very sensitive to changes in the size of the calculation domain, showing insignificant differences, while WS is. For instance, STC8 and STC11 are located in different extratropical environment of formation, associated with different WS, depending on the calculation box. Therefore, an interval of uncertainty should be introduced in the partitions of the environments although the results presented here (Fig. 6) are associated with a single grid box $\left(3^{\circ} \times 3^{\circ}\right.$ for SST and $6^{\circ} \times 6^{\circ}$ for WS) in order to be able to contrast them better with the other studies. The larger grid boxes have been chosen for a better representation of the structure of the cyclones.

The two parameters used above to obtain the classification of the STC environments are associated with processes that have been demonstrated to be involved in the development of cyclones. The ratio between these processes plays a decisive role in determining the final structure type (tropical, extratropical, or hybrid) attained by cyclones. Two of the large-scale conditions considered to be necessary but not sufficient for tropical cyclogenesis are weak wind shear and warm SST (Gray 1968; Evans 1993). As such, the tropical environment is the most favored of the four types for tropical cyclogenesis and thus the lack of STCs in this environment within the region of study is logical. The subtropical class also has a nearsurface thermodynamic forcing resulting from heat and moisture fluxes from the warm ocean below. However, it has an environment of strong wind shear, which increases the likelihood of baroclinic development and therefore is the most adequate environment for the subtropical cyclogenesis. A baroclinic system in the upper westerlies, consistent with QG theory, tends to force mass ascent, which, in close conjunction with the warm moist nearsurface layer, favors the generation of deep convection and decreasing static stability. In this neutral atmosphere, forced ascent can extend down to the surface and 
TABLE 2. Selected parameters associated with the STCs' environments (ENV) at their genesis $\left(t_{0}\right)$. Subscripts 1 and 2 are for the smaller and larger grid boxes, respectively.

\begin{tabular}{|c|c|c|c|c|c|c|}
\hline Storm & $\mathrm{SST}_{1}\left({ }^{\circ} \mathrm{C}\right)$ & $\mathrm{SST}_{2}\left({ }^{\circ} \mathrm{C}\right)$ & $\mathrm{WS}_{1}\left(\mathrm{~m} \mathrm{~s}^{-1}\right)$ & $\mathrm{WS}_{2}\left(\mathrm{~m} \mathrm{~s}^{-1}\right)$ & $\mathrm{ENV}_{1}$ & $\mathrm{ENV}_{2}$ \\
\hline STC1 & 22.73 & 22.74 & 17.95 & 18.44 & E1 & E1 \\
\hline STC2 & 14.81 & 14.83 & 15.33 & 15.82 & E1 & E1 \\
\hline STC3* & $6.07 *$ & $4.57 *$ & 34.47 & 34.18 & - & - \\
\hline STC4 (pre-Edouard) & 21.83 & 21.82 & 15.73 & 17.12 & E1 & E1 \\
\hline STC5 & 20.21 & 20.21 & 13.06 & 14.67 & E1 & E1 \\
\hline STC6 & 20.32 & 20.24 & 41.42 & 40.43 & E1 & E1 \\
\hline STC7 & 20.05 & 20.06 & 18.58 & 18.75 & E1 & E1 \\
\hline STC8 & 17.93 & 17.95 & 9.22 & 11.53 & $\mathrm{E} 2$ & E1 \\
\hline STC9 & 16.90 & 16.92 & 6.57 & 8.74 & E2 & E2 \\
\hline STC10 & 19.53 & 19.47 & 18.94 & 19.34 & E1 & E1 \\
\hline STC11 & 24.76 & 24.73 & 9.53 & 10.04 & E2 & E1 \\
\hline STC12 (pre-Vince) & 23.67 & 23.63 & 6.50 & 8.96 & E2 & E2 \\
\hline STC13 (pre-Delta) & 23.31 & 23.37 & 9.78 & 9.77 & E2 & E2 \\
\hline STC14 & 19.62 & 19.63 & 9.40 & 8.79 & E2 & E2 \\
\hline STC15 & 19.84 & 19.88 & 13.78 & 14.48 & E1 & E1 \\
\hline
\end{tabular}

* The cyclone does not originate completely over ocean surface.

convective feedback can lead to STC genesis and potentially also to tropical cyclogenesis. Nevertheless, this subtropical environment does not involve the formation of STCs in our case, as noted below.

In contrast, the extratropical environments (E1 and E2) are characterized by cold SST. Thus, the proximity of an upper-level trough will lead more likely to a baroclinic development of a more purely extratropical storm structure than tropical, since lower ocean surface temperatures tend to limit enthalpy fluxes at the storm's lower levels. Nevertheless, E2 environment is characterized by low wind shear, which may aid the maintenance of convection in case of its development and thus favors the accumulation of the released latent heat. This accumulation of heating leads to the building of the warm core in low levels of the troposphere, which is characteristic of an STC structure. If this process continues, the cyclone develops a tropical structure. To sum up, the successful development of the STC will then depend on the different acting forcings and on the extent in that they act.

The identified cyclones are classified in the diagram of Fig. 6 , in which the predominance $(71.4 \%)$ of the classical extratropical environment (E1), characterized by high wind shear and low SST values, is noticeable. Since STC3 formed just off the African coast, its SST values are inaccurate over the calculation domain and thus this cyclone must be left out of the environmental classification. It is worth noting that STC11 is located in the diagram remarkably close to the subtropical and tropical environments boundaries, originating over the warmest waters $\left(\sim 25^{\circ} \mathrm{C}\right)$ with respect to the other cyclones. This happens because of the season (October) when it formed. Warm SSTs come far to the north of their usual position in late summer and early autumn. The rest of the cyclones
$(28.6 \%)$ originate in the low-shear extratropical environment (E2) although they are all close to the boundary with E1. In addition, it can be seen that there is no linearity between SST and wind shear at the moment of the cyclones' formation. It is worth noting that 3 out of the 15 cases (STC4, STC12, and STC13) became officially (NHC) tropical cyclones after the subtropical development, which denotes the potential for the transition to tropical cyclones of these types of cyclones despite not having been surrounded by suitable environments (E1 and E2).

Unlike ENA STCs, WNA STCs formed predominantly in the subtropical $(38.9 \%)$ and tropical $(38.9 \%)$ environments. Of the 18 cyclones identified in the western basin (Evans and Guishard 2009), only one and three cyclones originated under E1 and E2 situations, respectively. This relative paucity of extratropical genesis environments is due to the focus on the hurricane season, which is reasonable given the observed high incidence of North Atlantic STC events (Guishard et al. 2009) during the hurricane season. This last-mentioned climatology highlights anew the predominance of both the subtropical $(33 \%)$ and tropical $(24.4 \%)$ environments, which is an indication that WNA STCs influence the climatological environmental features of North Atlantic STCs more than ENA STCs, although in this case E1 and E2 environments had a greater frequency with $23.4 \%$ and $19.3 \%$, respectively. In contrast, STCs over the South Atlantic (SA) mostly originated in the E1 environment (88\%) based upon the survey of Evans and Braun (2012), which indicates that ENA STCs resemble SA STCs more than WNA STCs.

As has been noted, the cyclones studied here differ from those originating within the WNA in their formation environments, and they are also a special case of North Atlantic STC. Indeed, the predominance of the 


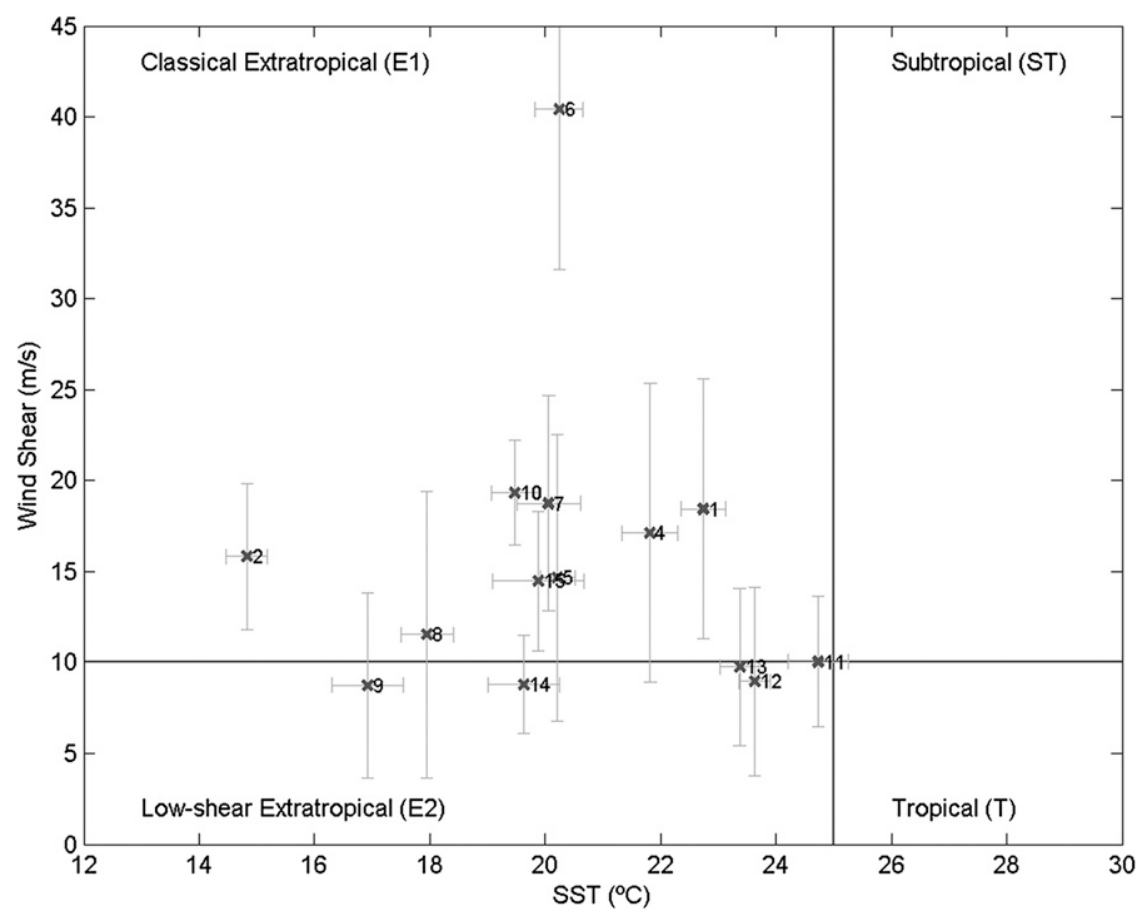

FIG. 6. Partition of the 14 STC cases based upon characteristics of their synoptic environment at genesis time $\left(t_{0}\right)$. Number is associated with the name of the cyclone. Uncertainty bars indicate the standard deviation.

extratropical environment when ENA STCs form is the main reason why they are frequently confused with extratropical depressions. This disagreement is reasonable given the difference in the climatological environment between the two basins and may also suggest different environments in which an STC originates. Therefore, as was also noted in section 3 , it can be deduced that ENA STCs are more similar to extratropical cyclones whereas WNA STCs are more similar to tropical cyclones. However, both types of STCs can have the same impact and even both can make a transition to a tropical cyclone in the same manner. For instance, STC4, STC12, and STC13 were ENA STCs that then evolved into tropical cyclones (Case 1990; Franklin 2006; Beven 2006), as happened in the case of Hurricanes Karen or Michael within the WNA (Evans and Guishard 2009).

The potential development of the eastern STCs in an unsuitable environment characterized by high wind shear and low SST may be explained by two fundamental reasons. On the one hand, as was noted with WNA STCs, convection might be forced either by development over warm SST or warm-air advection for ultimately inducing a hybrid STC structure. In this way, analyzing moist-air advection from the tropics when precursors of STC move southward might also provide some responses. On the other hand, genesis and maintenance of subtropical structures in a high shear environment may be due to shallow convection that accompanies these systems, as may also happen in tropical cyclones that form in environments with cool SST and high wind shear over the northeastern Atlantic Ocean. These types of tropical cyclones were studied by Mauk and Hobgood (2012). They found that the reduced depth of convection associated with tropical cyclones from nontropical precursors limits the effects of 850-200-hPa wind shear on those systems. This result would be supported by the higher sensitivity to the wind shear of tropical cyclones developing over high SSTs found by Nolan and Rappin (2008). Therefore, it is possible that the presence of low SSTs may reduce the sensitivity of tropical cyclones to wind shear by inducing shallower convection.

\section{Synoptic classification of subtropical cyclogenesis}

As already mentioned, one of the goals of this survey is to bring some operational assistance to forecasters. With this in mind, this section focuses on the aid consisting of identification and monitoring of atmospheric situations that are conducive to the development of STCs that can represent a threat for the countries of the eastern Atlantic coast. This objective is addressed by examining subjectively the $300-\mathrm{hPa}$ geopotential height field at $t_{0}$ for the 15 cases so as to capture the main features of atmospheric 
patterns over the Atlantic Ocean basin when the identified STCs were forming. Based upon this analysis, one might argue that STCs formed within the ENA region tend to be developed according to one of the three idealized models shown in Fig. 7.

The cutoff/isolation model (Fig. 7a) idealizes the typical situation in which a depression embedded in the zonal flow cuts off from this. The circulation just to the north continues to be zonal and slightly undulated without great deformations although it tends to move to the north. Occasionally, the surface low is not originated by an upper cutoff depression but it may be formed by a trough that is not associated with the midlatitude circulation [a tropical upper tropospheric trough (TUTT)]. STC1, STC4, STC10, STC11, STC12, and STC14 are the cyclones fitting this first model.

The bifurcation model (Fig. 7b) whose main feature is a blocked pattern flow with the center of the ridge/ high located in the vicinity of the British Isles. It resembles a Rex block, as was noted in WNA STCs. This pattern fosters the appearance of an extratropical jet becoming undulated. STCs form just to the southeast of the ridge. STC2, STC5, STC9, STC13, and STC15 are associated with this model.

The prolongation conceptual model (Fig. 7c) is associated with a highly meridional circulation as well, although in this case it is stimulated by a marked elongation northward of the subtropical ridge with its axis in a southwest-northeast orientation within the mid-Atlantic Ocean. There exists a depression (STC) just to the southeast of the subtropical ridge, which is a prolongation of a primary trough associated with the westerlies and located over central Europe. Occasionally, the subtropical ridge may be related to an omega blocked flow pattern. STC3, STC6, STC7, and STC8 fit this last model. This model is different from the cutoff/isolation model in that the midlatitude circulation seems to be highly disturbed with a great meridional movement mainly due to the displacement of the subtropical ridge toward the north.

The main common feature of the three described conceptual models is the notable departure from the climatological atmospheric circulation, as was remarked in section 4. This deviation is related to the fact that the westerly circulation is shifted poleward and/or is characterized by a large meridional component of the flow with even the possibility of the appearance of a blocked flow pattern. Therefore, the synoptic classification just described could also usefully complement the information on the composite anomalies, which can be explained by the deviations mentioned.

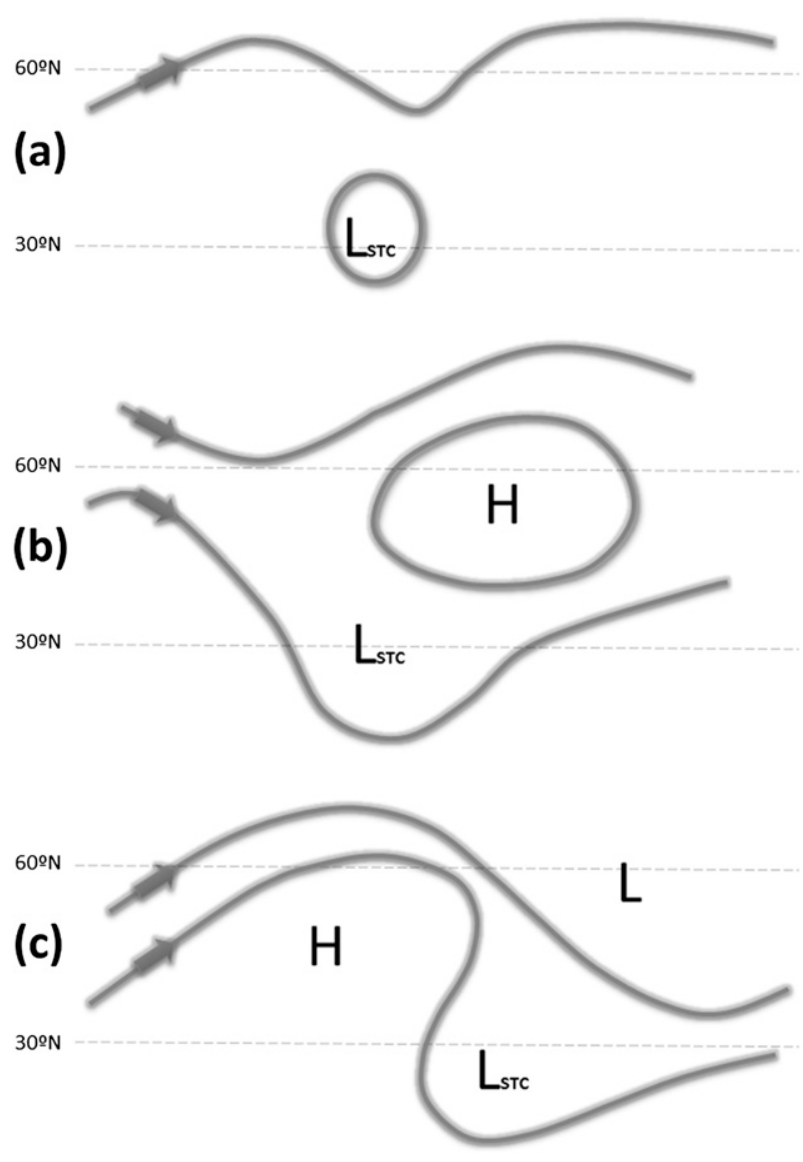

FIG. 7. Conceptual models of geopotential height at $300-\mathrm{hPa}$ patterns at the formation of the cyclones $\left(t_{0}\right)$ : (a) cutoff/isolation, (b) bifurcation, and (c) prolongation. The arrows indicate the approximately sense of the flow at $300 \mathrm{hPa} ; \mathrm{H}$ denotes a region of high pressure and $\mathrm{L}$ denotes a region of low pressure, where the subscript STC denotes the subtropical cyclone.

Results obtained in this section need to be complemented with more research in order to be of further help to forecasting community. For instance, one aspect of interest would be to perform some kind of evaluation of the frequency of these patterns. Another useful issue could be to analyze the probability of occurrence of formation of an STC when one of the model patterns is identified. This topic is hoped to be addressed by the authors in a future paper, in conjunction with the search of teleconnection patterns that might favor the appearance of STCs within the ENA.

\section{Case study: Synoptic evolution of STC15}

The synoptic history of the STC formed in 2010 (see Table 1) is described here in a way that can help to achieve a more detailed view of the results obtained in the previous sections. In addition, other characteristics 

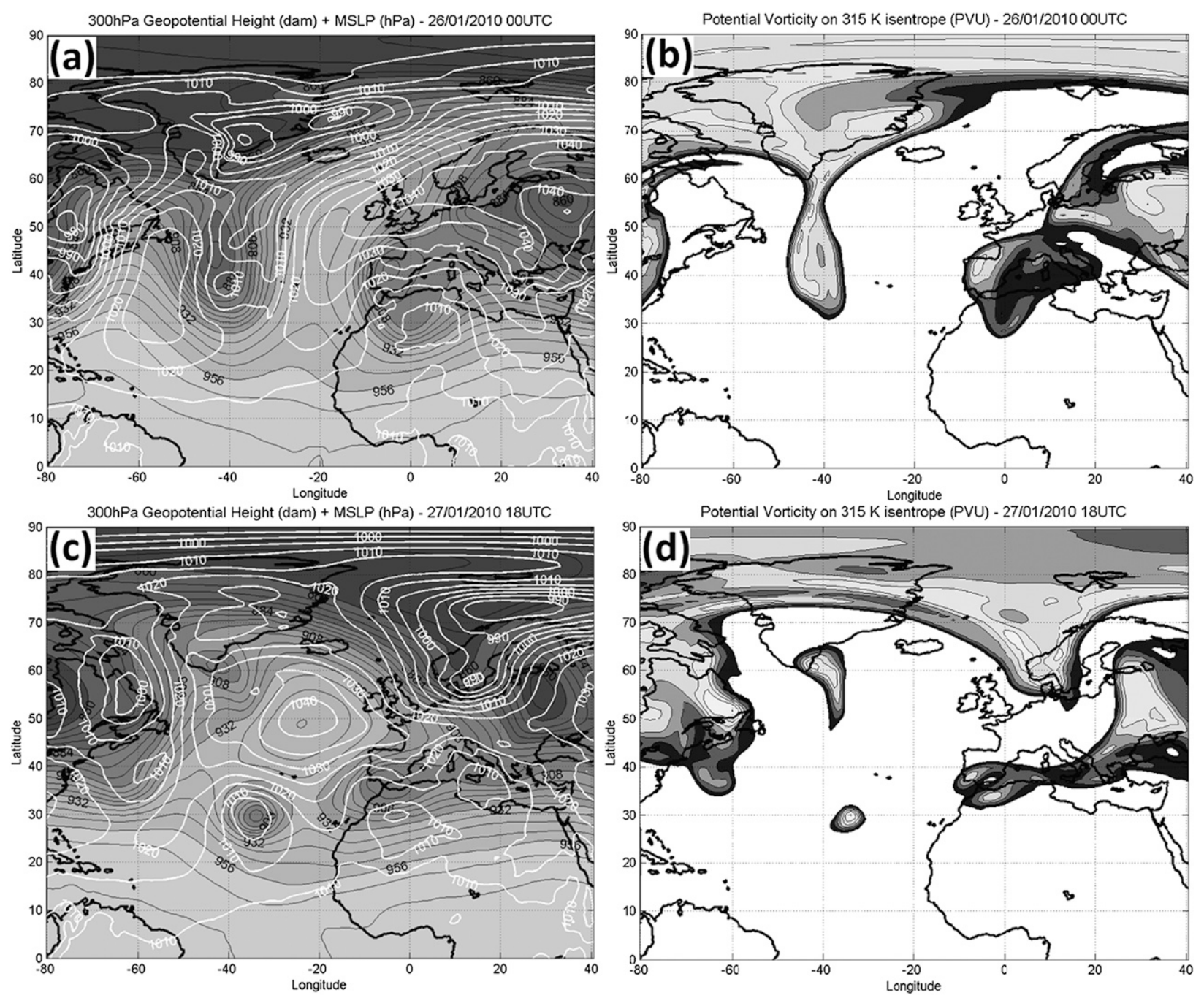

FIG. 8. Geopotential height (shaded and gray contours; dam) at $300 \mathrm{hPa}$ and MSLP (white contours; hPa) at (a) $0000 \mathrm{UTC} 26 \mathrm{Jan}$ and (c) 1800 UTC 27 Jan 2010. Also shown is potential vorticity on the $315-\mathrm{K}$ potential temperature surface (shaded) at (b) 0000 UTC 26 Jan and (d) 1800 UTC 27 Jan 2010. The grayscale color interval for (b) and (d) is 1 PVU starting at 2 PVU [1 potential vorticity unit (PVU) = $\left.10^{-6} \mathrm{~K} \mathrm{~kg}^{-1} \mathrm{~m}^{2} \mathrm{~s}^{-1}\right]$.

are detailed in order to justify the recognition of this system as subtropical and its inclusion in our database.

During 24 and 25 January 2010, the atmospheric circulation over the North Atlantic is characterized by a notable undulation in the geopotential field, associated with a Rossby wave that has both significant amplitude and wavelength. This wave favors the formation of a ridge over the eastern North Atlantic with its axis located just to the west of the Iberian Peninsula, and also favors the existence of a trough over the western North Atlantic, located to the north of Bermuda. The persistence of this trough over a baroclinic zone brings about the repeated formation of depressions downstream by QG forcing. By 26 January, the elongation of the ridge northward and the trough southward produce an omega blocked pattern flow as can be seen in Fig. 8a. By the next day, the resulting digging trough has formed a cutoff cyclone (Fig. 8c). Therefore, the surface low is now sustained by the upper positive PV anomaly inducing a cyclonic circulation that weakens toward the ground, aided by the weakly stable environment underneath (Hoskins et al. 1985). This described atmospheric pattern is consistent with the results obtained in section 4 , with an upper-level ridge and its associated surface anticyclone to the west of the British Isles, and a region of low pressure just to the south of the ridge, which developed into STC15.

From a PV perspective, by the 26 January a cyclonic Rossby wave breaking (RWB) event [life cycle 2 (LC2); Thorncroft et al. 1993] can be identified to the northwest of Azores (Fig. 8b). There also exists an anticyclonic RWB 
[life cycle 1 (LC1)] just to the west of the cyclonic RWB. Both RWBs promote the break of the serpentine-shaped pattern and the isolation of relatively high potential vorticity values associated with the cutoff low mentioned above (Fig. 8d). At the same time, a RWB-type LC1 is occurring just to the north of Iberian Peninsula. All these wavebreaking events are associated with the omega blocked flow pattern referred to above. RWBs were found to have accompanied the formation of WNA STCs and events that suffered tropical transitions (Davis and Bosart 2003) as well. In fact, Evans and Guishard (2004) took this phenomenon into consideration when they proposed a potential vorticity mechanism for subtropical cyclogenesis and tropical transition.

Once the depression is cut off from the westerlies and diminishes its horizontal scale, the atmospheric pattern remains nearly stationary because of the blocked flow pattern, making the low pressure region persist isolated from the general circulation (i.e., detached from the main baroclinic zone). The surrounding environment then becomes more barotropic and the cyclone begins to occlude. This barotropic environment, in conjunction with the stationarity of the cyclone, provokes a decreasing in vertical wind shear from $28 \mathrm{~m} \mathrm{~s}^{-1}$ at $24 \mathrm{~h}$ prior to the formation of the STC to $4 \mathrm{~ms}^{-1}$ at $24 \mathrm{~h}$ afterward. However, the system formed in an environment type E1 with high wind shear $\left(\sim 14.5 \mathrm{~m} \mathrm{~s}^{-1}\right)$, as seen in section 5 , which is provided by a negatively tilted secondary upper-level trough located to the west of the cyclone. This seems to imply that the subtropical cyclogenesis was not caused by the decrease in vertical wind shear. In contrast, this cyclogenesis is likely to have caused the sharp wind shear weakening due to vertical distribution of $\mathrm{PV}$ as mentioned in section $4 \mathrm{~b}$, and the above described synoptic environment could have been involved in the subsequent STC maintenance.

Two days after the isolation of the precursor cyclone from the midlatitude circulation, a remarkable deepening of about $10 \mathrm{hPa}$ takes place (not shown) once it experiences the transition to a subtropical stage. This deepening differs from the classical decay of extratropical cyclones at the end of their life cycles as the baroclinicity is removed and the cyclone fills. This feature also supports the results of storm-centered composites described in section $4 \mathrm{~b}$ and implies that the cyclone is mostly governed by the PV positive anomaly created in the lower troposphere, which is caused by latent heat released by the significant convection originated around the center of the cyclone, as is shown below. In addition, a weakening of the ridge located to the east of the cyclone is evident from the temporal animation of the synoptic pattern (not shown), which, added to the positioning of this ridge just to the north of the cyclone as time approaches the moment $t_{0}$, is also in agreement with storm-center composites. Yet there is no strengthening of its associated surface high pressure after the subtropical cyclogenesis.

A fundamental feature of the atmospheric circulation over the North Atlantic during this episode is the persistence of the blocked flow, whose pattern is associated with the bifurcation conceptual model described in section 6. Furthermore, as Fig. 9 shows, as time approaches the moment of the subtropical cyclogenesis $\left(t_{0}\right)$, the anomaly pattern over the North Atlantic tends to resemble the anomaly composite map (Fig. 3b) of section $4 \mathrm{a}$, with positive anomalies around $60^{\circ} \mathrm{N}$ and negative anomalies around $30^{\circ} \mathrm{N}$ associated with the cyclone. This pattern shows the potential for a subtropical development $60 \mathrm{~h}$ prior to the formation of the STC. However, after the time $t_{0}$ there is not any strengthening of the upper and surface positive anomalies to the north of the cyclone anomaly (not shown), which is related to the abovementioned lack of reinforcement of the ridge and surface high pressure, thus being not supported by Figs. $5 \mathrm{~d}-\mathrm{f}$ described in section $4 \mathrm{~b}$ either.

The series of satellite images (Fig. 10) reveals perfectly the transformation of the cloudiness pattern associated with the cyclone during its life cycle. Once the cyclone cuts off from the westerlies, it experiences the transition from a baroclinic environment to an increasingly barotropic state. This barotropic environment is related to the disappearance of the frontal structures. The depression has initially an asymmetric pattern (Fig. 10a) whose fronts then tend to disappear (Figs. 10b,c), with scattered convective cloudiness mostly created as a result of the thermal forcing of the upper troposphere cold core. The most eastern convective clouds are hypothesized to be generated by residual QG forcing. The decreasing of the wind shear, as noted above, down to $4 \mathrm{~m} \mathrm{~s}^{-1}$ about $24 \mathrm{~h}$ after starting the subtropical cyclogenesis, might have helped the formation of a formidable convective cell (Fig. 10c), resembling the typical convective cloudiness pattern of tropical cyclones. Nevertheless, this cyclone exhibits a relatively convection-free circulation center in comparison with the tropical cyclones, which often have deep and persistent convection at their centers. It is worth noting the similarity of the cloudiness pattern of this cyclone to that of the Tropical Storm Grace, which also originated in a nearly stationary occluding low near the Azores in early October 2009 (Mauk and Hobgood 2012).

The CPS (Hart 2003) is used here to complement the synoptic history and satellite images of the cyclone. ERA-Interim data were used to derive the CPS path through the life cycle of STC15 (Fig. 11). As can be deduced from Fig. 11a, the system began on 27 January with a cold anomaly at both low levels $(900-600 \mathrm{hPa})$ 


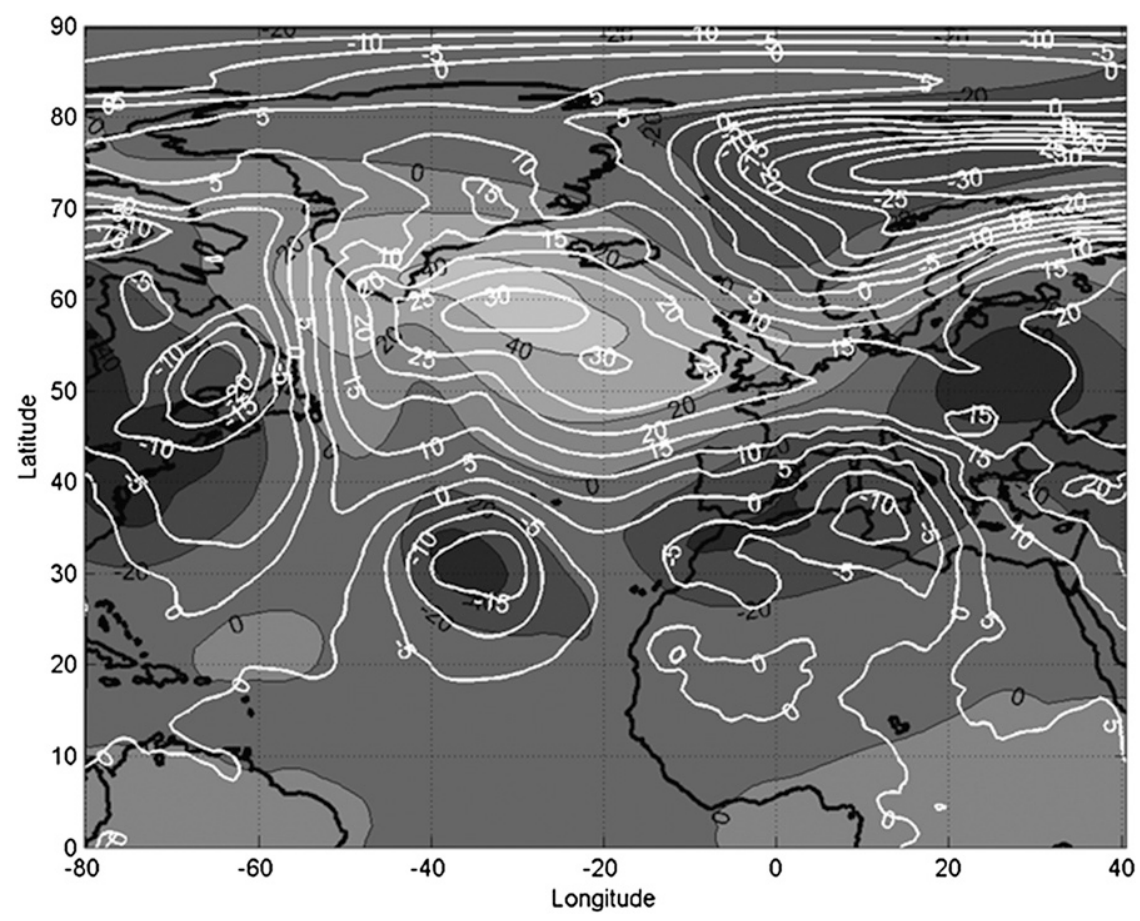

FIG. 9. Anomaly of geopotential height (shaded; dam) at $300 \mathrm{hPa}$ and anomaly of MSLP (white contours; hPa) at 0600 UTC 27 Jan 2010.

and upper levels $(600-300 \mathrm{hPa})$ - that is, with a deep cold core-and therefore it was a purely extratropical depression. By 1800 UTC 29 January, the storm had become a shallow warm-core system, consistent with a STC structure, and even by 30 January the system contained a moderate warm core when it started to have a warm thermal anomaly aloft for several hours, which is more consistent with the structure of a tropical cyclone. Thus, it is worth noting that despite the low SST values $\left(\sim 20^{\circ} \mathrm{C}\right)$, consistent with the season when it developed (winter), the storm almost suffered a complete tropical transition, which might have been favored by the stationarity and the decreased wind shear mentioned above. Later on, the system became extratropical again by 1200 UTC 31 January (after $36 \mathrm{~h}$ ) and remained with a mix of hybrid and extratropical structure during the next four days. It is likely that real thermal anomalies were deeper than those shown here since the CPS based on GFS analysis $\left(0.5^{\circ}\right)$ and Climate Forecast System Reanalysis (CFSR; $0.5^{\circ}$ ) show a significant shallow warm core on 3 and 4 of February (see link in Fig. 11), which would suggest the need for a mesoscale study of these types of cyclones.

Based upon Fig. 11b, the system appears to have formed in a baroclinic environment $(B \sim 50)$, consistent with an
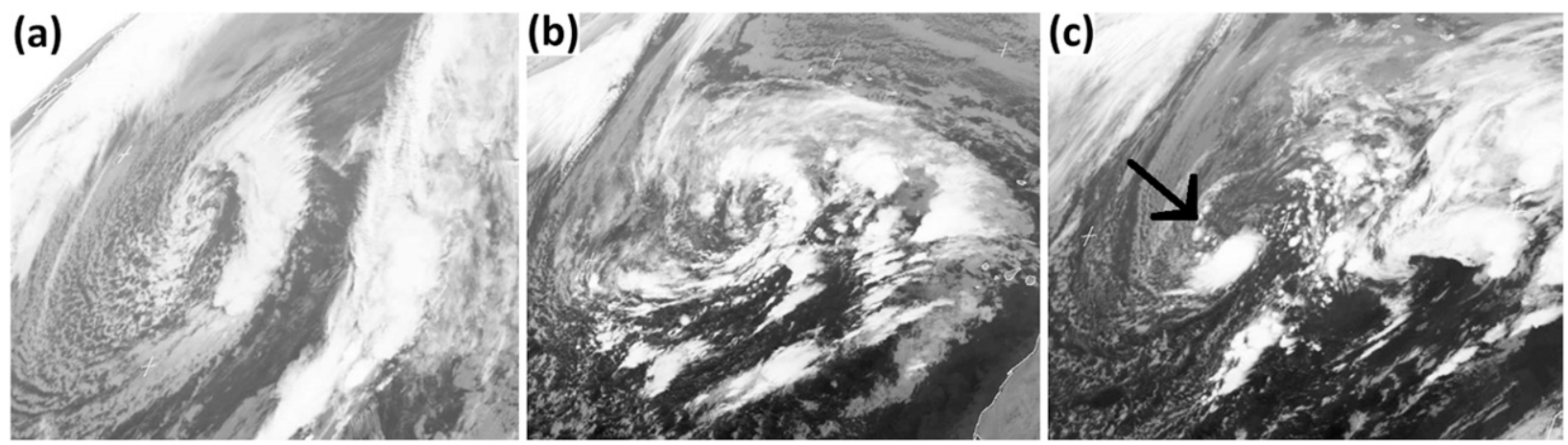

FIG. 10. Sequence of satellite imagery [channel 9 from Meteosat Second Generation 2 (MSG2 or Meteosat-9)] during the development of STC15 at (a) 1200 UTC 26 Jan, (b) 0600 UTC 30 Jan, and (c) 0000 UTC 31 Jan 2010. Source: EUMETSAT-Dundee Satellite Receiving Station (University of Dundee). 

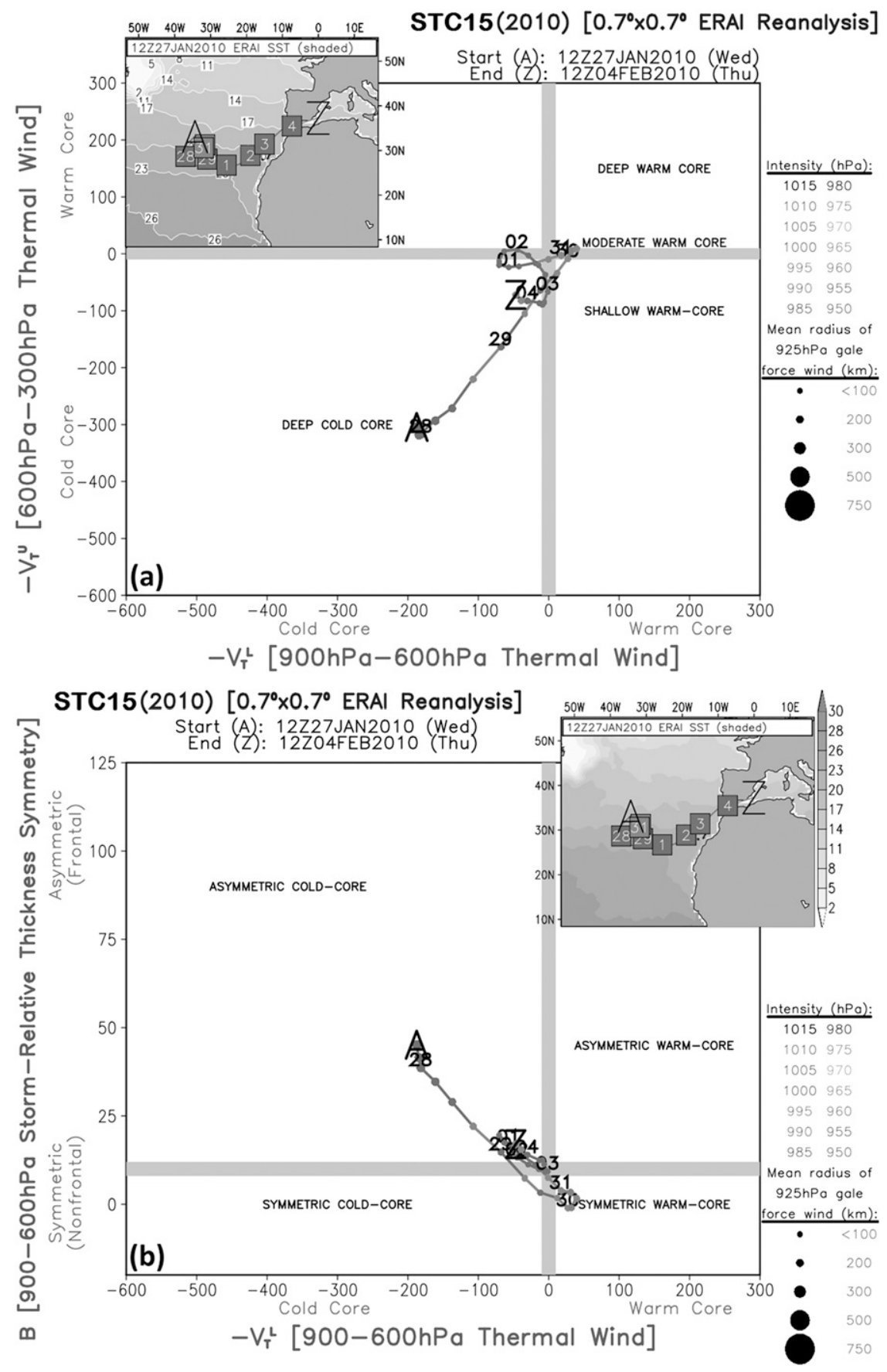

FIG. 11. ERA-Interim of STC15 plotted in the CPS: (a) $V_{T}^{L}$ vs $V_{T}^{U}$ and (b) $V_{T}^{L}$ vs $B$. The $\mathrm{A}$ indicates the beginning of the plotted life cycle within the reanalysis and the $\mathrm{Z}$ indicates the end. A marker is placed every $6 \mathrm{~h}$. The shading of each marker indicates cyclone MSLP intensity and the size of the circular marker indicates the relative size (mean radius) of the 925-hPa gale-force $\left(>17 \mathrm{~m} \mathrm{~s}^{-1}\right)$ wind field. Positions at 0000 UTC are labeled with the day. (Available online at http://moe.met.fsu.edu/cyclonephase/archive/2010/gifs/juanje32010/).

extratropical structure, tending to occlude when moving toward a weak baroclinic environment $(B \sim 0)$, which is in agreement with the satellite images shown in Fig. 10 and the isolation of the cyclone from the westerlies. By
30 January, the system already contained a symmetric (nonfrontal) warm-core cyclone and remained nearly symmetric up to the end of its life cycle based on the CPS. The mean radius of $925-\mathrm{hPa}$ gale-force winds is 
also shown in Fig. 11, decreasing from $<300$ to $<200 \mathrm{~km}$ by the end of the day 28 , when the cyclone started to go directly toward a subtropical structure. This weakening was also perceived on day 31 , involving a cyclonic structure with a radius around $100 \mathrm{~km}$.

The CPS reinforces thus the idea of the subtropical behavior of the depression from a thermal point of view, which, added to the gale-force winds, matches the main features for a cyclone to be considered an STC based on the criteria (see section 2a) employed in ERA-40 climatology, as discussed in section 2c. Therefore, STC15 is a suitable candidate for being included in our study. It should be noted that despite the fact that the cyclone was in the tropical cyclone region in the CPS for several hours (i.e., $-\left|V_{T}^{L}\right|>-10$ and $-\left|V_{T}^{U}\right|>-10$ ), we decided that this is not a fundamental reason to exclude this system from the set of ENA STCs, given its transitional nature and observed genesis environment (GonzálezAlemán et al. 2014). All the characteristics mentioned above together with the evolution toward a symmetric depression in the CPS are in agreement with the STC definition of $\mathrm{NHC}$, which made it a suitable candidate for being monitored by the NHC.

\section{Conclusions}

By applying a set of criteria from two databases, a total of 15 STCs were identified to form during the period of 1979-2011 within the ENA and have been examined from a synoptic point of view, on a climatological basis, in this study.

October-March is their preferred season with 14 of these cases. Storm-centered composites (section $4 \mathrm{~b}$ ) depicted an extratropical cyclone as a precursor embedded in the westerly circulation that was undergoing a process of detachment and isolation from the midlatitude flow and gradually acquired the characteristics of an STC with an associated deepening, rather than a weakening as would be expected for a typical midlatitude depression after its evolution into a cutoff low. Another issue worth highlighting in these composites is the presence of a ridge intensifying just to the north of the cyclonic anomaly, which gives added strength to the idea that the cyclone becomes increasingly isolated.

The North Atlantic basin composite maps (section 4a) revealed a synoptic pattern different from the climatological counterpart, corresponding to a large region of positives anomalies to the north of the North Atlantic $\left(\sim 60^{\circ} \mathrm{N}\right)$ and a region of negative anomalies to the south $\left(\sim 30^{\circ} \mathrm{N}\right)$. The causes of this deviation were demonstrated, in section 6 , to be due to a northward displacement of the westerly circulation and/or a large meridional component of the flow with even the possibility of appearance of a blocked flow pattern. These features were identified in the synoptic classification of subtropical cyclogenesis, in which the genesis-related synoptic patterns were separated into three conceptual models based on the geopotential height at $300 \mathrm{hPa}$ (i.e., cutoff/isolation, bifurcation, and prolongation). In our opinion, this might be of special interest to forecasters of eastern Atlantic to anticipate the formation of an STC by only examining the atmospheric synoptic pattern.

The analysis of the environmental features that affected the cyclone at its formation phase was evaluated through SST and vertical wind shear, leading to the environmental classification in section 5. This analysis noted that ENA STCs seem to occur in a high wind shear $\left(>10 \mathrm{~m} \mathrm{~s}^{-1}\right)$ and cold SST $\left(<25^{\circ} \mathrm{C}\right)$ environment (E1), with $71.4 \%$ of the cyclones being developed in this state. The other $28.6 \%$ of the cyclones formed in the E2, characterized by lower wind shear $\left(\leq 10 \mathrm{~m} \mathrm{~s}^{-1}\right)$. This causes ENA STCs to differ from their western counterparts (Evans and Guishard 2009) as regards their initial environments, making them a special case of North Atlantic STC (Guishard et al. 2009). ENA STCs have more similarities to extratropical cyclones while WNA STCs are more similar to tropical cyclones. However, ENA STCs tend to resemble SA STCs (Evans and Braun 2012) since substantial subsets of both types of STC form in the open ocean, in regions of much stronger shear and cooler SSTs than WNA STCs.

Finally, the above analysis was complemented with the study of the evolution of the cyclone originated in 2010 (STC15), which allowed us to interpret the general results more specifically. Consistent with results of section 4, STC15 was a typical extratropical cyclone in its early stage that detached from the midlatitude circulation and became a stationary cutoff low. It then underwent a transition from extratropical into subtropical cyclone in an atmospheric blocked pattern different from the climatology, leading to its inclusion in the bifurcation conceptual model of the synoptic classification undertaken in section 6 . When becoming subtropical the system underwent a deepening, which matches reasonably well the storm-centered composites. The cyclone's path in the CPS was also described, showing a shallow warm core, and it even almost attained a completely tropical thermal structure, which represents the potential for a tropical cyclone genesis mechanism from a subtropical stage.

Certain questions have arisen, which motivates more research on ENA STCs. Apart from the basis for a future objective climatology of STCs within the ENA, which takes into consideration their special characteristics, the authors consider that this work opens up new lines of study in this subject in the selected spatial 
domain with the objective of answering the following main questions: Why are convection and warm core sustained in high wind shear and low SST environments? Is there any atmospheric pattern that most favors the subtropical cyclogenesis? Are STCs related to any teleconnection pattern? Is there any relation between them and global warming? And the crucial question: Which factors induce a subtropical structure in an extratropical depression that is isolated from the westerlies? Or in other words, what differences exist in the environment, when cyclones become isolated from the westerlies, between an extratropical cyclone that occludes and an extratropical one that becomes subtropical?

Acknowledgments. Comments from three anonymous reviewers and the editor, to whom the authors are grateful, greatly improved this manuscript. We highly appreciate the data of subtropical cyclones provided by Dr. Mark P. Guishard from The Pennsylvania State University. We thank Dr. Robert E. Hart from The Florida State University for providing us the cyclone phase diagrams as well. We are also grateful to Dr. Francisco Doblas-Reyes from the Catalan Institute of Climate Sciences for his valuable comments and recommendations. This work was supported under a MECD Grant (Spanish government), the MINECO projects CGL2011-25327 and PCIN-2014-013-C07-04 (Spanish government), and by the U.S. National Science Foundation under Grant ATM1322532. Discussions with D. Iñigo Gómara and Dr. David Barriopedro from Complutense University of Madrid about RWB and blockings, respectively, are also appreciated.

\section{REFERENCES}

Beven, J. L., 2006: Tropical cyclone report: Tropical Storm Delta, 22-28 November 2005. National Hurricane Center, 12 pp.

Bjerknes, J., and H. Solberg, 1922: Life cycle of cyclones and the polar front theory of atmospheric circulation. Geophys. Norv., 3, 1-18.

Browning, S. A., and I. D. Goodwin, 2013: Large-scale influences on the evolution of winter subtropical maritime cyclones affecting Australia's East Coast. Mon. Wea. Rev., 141, 24162431, doi:10.1175/MWR-D-12-00312.1.

Case, R. A., 1990: Preliminary tropical cyclone report: Tropical Storm Edouard, 02-11 August 1990. National Hurricane Center. [Available online at http://www.nhc.noaa.gov/archive/ storm_wallets/atlantic/at11990-prelim/edouard/.]

Charney, J. G., 1947: The dynamics of long waves in a baroclinic westerly current. J. Meteor., 4, 135-161, doi:10.1175/ 1520-0469(1947)004<0136:TDOLWI >2.0.CO;2.

—, and A. Eliassen, 1964: On the growth of the hurricane depression. J. Atmos. Sci., 21, 68-75, doi:10.1175/1520-0469(1964)021<0068: OTGOTH $>2.0 . \mathrm{CO} ; 2$.
Davis, C. A., and L. F. Bosart, 2003: Baroclinically induced tropical cyclogenesis. Mon. Wea. Rev., 131, 2730-2747, doi:10.1175/ 1520-0493(2003)131<2730:BITC > 2.0.CO;2.

Dee, D. P., and Coauthors, 2011: The ERA-Interim reanalysis: Configuration and performance of the data assimilation system. Quart. J. Roy. Meteor. Soc., 137, 553-597, doi:10.1002/ qj. 828 .

Doblas-Reyes, F. J., M. J. Casado, and M. A. Pastor, 2002: Sensitivity of the Northern Hemisphere blocking frequency to the detection index. J. Geophys. Res., 107 (D2), doi:10.1029/ 2000JD000290.

Dvorak, V. F., 1975: Tropical cyclone intensity analysis and forecasting from satellite imagery. Mon. Wea. Rev., 103, 420-430, doi:10.1175/1520-0493(1975)103<0420:TCIAAF >2.0.CO;2.

Eady, E. T., 1949: Long waves and cyclone waves. Tellus, 1, 33-52, doi:10.1111/j.2153-3490.1949.tb01265.x.

Emanuel, K. A., 1986: An air-sea interaction theory for tropical cyclones. Part I: Steady-state maintenance. J. Atmos. Sci., 43, 585605, doi:10.1175/1520-0469(1986)043<0585:AASITF>2.0.CO;2. , 1988: Toward a general theory of hurricanes. Amer. Sci., 76, 370-379.

Evans, J. L., 1993: Sensitivity of tropical cyclone intensity to sea surface temperature. J. Climate, 6, 1133-1140, doi:10.1175/ 1520-0442(1993)006<1133:SOTCIT>2.0.CO;2.

- and M. P. Guishard, 2004: A proposed potential vorticity mechanism for sub-tropical cyclogenesis and tropical transition. Preprints, 26th Conf. on Hurricanes and Tropical Meteorology, Miami, FL, Amer. Meteor. Soc., P1.90. [Available online at https://ams.confex.com/ams/pdfpapers/75133. pdf.]

, and —, 2009: Atlantic subtropical storms. Part I: Diagnostic criteria and composite analysis. Mon. Wea. Rev., 137, 2065-2080, doi:10.1175/2009MWR2468.1.

, and A. Braun, 2012: A climatology of subtropical cyclones in the South Atlantic. J. Climate, 25, 7328-7340, doi:10.1175/ JCLI-D-11-00212.1.

Franklin, J. L., 2006: Tropical cyclone report: Hurricane Vince, 8-11 October 2005. National Hurricane Center, 9 pp.

González-Alemán, J. J., F. Valero, and F. Martín-León, 2014: How to detect a subtropical cyclone. 33nd Scientific Conf. of the Spanish Meteorological Association, Oviedo, Spain. [Available online (in Spanish) at http://www.ame-web.org/images/stories/Congresos/ 33-Oviedo/TabajosCompletosJornadas/4.analisis_y_prediccion_ del_tiempo/Oral_GonzalezAleman.pdf.]

Gray, W. M., 1968: Global view of the origin of tropical disturbances and storms. Mon. Wea. Rev., 96, 669-700, doi:10.1175/ 1520-0493(1968)096<0669:GVOTOO>2.0.CO;2.

Guishard, M. P., E. A. Nelson, J. L. Evans, R. E. Hart, and D. G. O'Connell, 2007: Bermuda subtropical storms. Meteor. Atmos. Phys., 97, 239-253, doi:10.1007/s00703-006-0255-y.

_ J. L. Evans, and R. E. Hart, 2009: Atlantic subtropical storms. Part II: Climatology. J. Climate, 22, 3574-3594, doi:10.1175/ 2008JCLI2346.1.

Gyakum, J. R., 1983a: On the evolution of the QE II storm. I: Synoptic aspects. Mon. Wea. Rev., 111, 1137-1155, doi:10.1175/ 1520-0493(1983)111<1137:OTEOTI >2.0.CO;2.

, 1983b: On the evolution of the QE II storm. II: Dynamic and thermodynamic structure. Mon. Wea. Rev., 111, 1156-1173, doi:10.1175/1520-0493(1983)111<1156:OTEOTI >2.0.CO;2.

Hart, R. E., 2003: A cyclone phase space derived from thermal wind and thermal asymmetry. Mon. Wea. Rew., 131, 585-616, doi:10.1175/1520-0493(2003)131<0585:ACPSDF>2.0.CO;2. 
Hebert, P. H., and K. O. Poteat, 1975: A satellite classification technique for subtropical cyclones. NOAA Tech. Memo. NWS SR-83, 25 pp. [Available online at http://docs.lib.noaa.gov/ noaa_documents/NWS/NWS_SR/TM_NWS_SR_83.pdf.]

Holland, G. J., A. H. Lynch, and L. M. Leslie, 1987: Australian eastcoast cyclones. Part I: Synoptic overview and case study. Mon. Wea. Rev., 115, 3024-3036, doi:10.1175/1520-0493(1987)115<3024: AECCPI $>2.0 . \mathrm{CO} ; 2$.

Holton, J. R., 2004: An Introduction to Dynamic Meteorology. Academic Press, 535 pp.

Hoskins, B. J., M. E. McIntyre, and A. W. Robertson, 1985: On the use and significance of isentropic potential vorticity maps. Quart. J. Roy. Meteor. Soc., 111, 877-946, doi:10.1002/ qj.49711147002.

Jarvinen, B. R., C. J. Neumann, and M. A. S. Davis, 1984: A tropical cyclone data tape for the North Atlantic basin, 1886-1983: Contents, limitations, and uses. NOAA Tech. Memo. NWS NHC 22, 21 pp. [Available online at http://www.nhc.noaa.gov/ pdf/NWS-NHC-1988-22.pdf.]

Knapp, K. R., M. C. Kruk, D. H. Levinson, H. J. Diamond, and C. J. Neumann, 2010: The International Best Track Archive for Climate Stewardship (IBTrACS): Unifying tropical cyclone data. Bull. Amer. Meteor. Soc., 91, 363-376, doi:10.1175/2009BAMS2755.1.

Kuo, H. L., 1965: On formation and intensification of tropical cyclones through latent heat release by cumulus convection. J. Atmos. Sci., 22, 40-63, doi:10.1175/1520-0469(1965)022<0040: OFAIOT $>2.0 . \mathrm{CO} ; 2$.

Landsea, C. W., 2007: Counting Atlantic tropical cyclones back to 1900. Eos, Trans. Amer. Geophys. Union, 88, 197-202.

Mauk, R. G., and J. S. Hobgood, 2012: Tropical cyclone formation in environments with cool SST and high wind shear over the northeastern Atlantic Ocean. Wea. Forecasting, 27, 14331448, doi:10.1175/WAF-D-11-00048.1.
McBride, J. L., and R. Zehr, 1981: Observational analysis of tropical cyclone formation. Part II: Comparison of non-developing versus developing systems. J. Atmos. Sci., 38, 1132-1151, doi:10.1175/ 1520-0469(1981)038<1132:OAOTCF $>2.0 . C O ; 2$.

Nieto, R., and Coauthors, 2005: Climatological features of cutoff low systems in the Northern Hemisphere. J. Climate, 18, 30853103, doi:10.1175/JCLI3386.1.

Nolan, D. S., and E. D. Rappin, 2008: Increased sensitivity of tropical cyclogenesis to wind shear in higher SST environments. Geophys. Res. Lett., 35, L14805, doi:10.1029/2008GL034147.

Ooyama, K., 1969: Numerical simulation of the life-cycle of tropical cyclones. J. Atmos. Sci., 26, 3-40, doi:10.1175/ 1520-0469(1969)026<0003:NSOTLC >2.0.CO;2.

Otkin, J. A., and J. E. Martin, 2004: A synoptic climatology of the subtropical kona storm. Mon. Wea. Rev., 132, 1502-1517, doi:10.1175/1520-0493(2004)132<1502:ASCOTS>2.0.CO;2.

Raymond, D. J., 1992: Nonlinear balance and potential-vorticity thinking at large Rossby number. Quart. J. Roy. Meteor. Soc., 118, 987-1015, doi:10.1002/qj.49711850708.

Romero, R., 2001: Sensitivity of a heavy-rain-producing western Mediterranean cyclone to embedded potential-vorticity anomalies. Quart. J. Roy. Meteor. Soc., 127, 2559-2597, doi:10.1002/ qj. 49712757805 .

Rotunno, R., and K. A. Emanuel, 1987: An air-sea interaction theory for tropical cyclones. Part II: Evolutionary study using a nonhydrostatic axisymmetric numerical model. $J$. Atmos. Sci., 44, 542-561, doi:10.1175/1520-0469(1987)044<0542: AAITFT $>2.0 . \mathrm{CO} ; 2$.

Steward, S. R., 2001: Tropical cyclone report: Hurricane Karen, 1215 October 2001. National Hurricane Center, 10 pp.

Thorncroft, C. D., B. J. Hoskins, and M. E. McIntyre, 1993: Two paradigms of baroclinic-wave life-cycle behaviour. Quart. J. Roy. Meteor. Soc., 119, 17-55, doi:10.1002/qj.49711950903. 